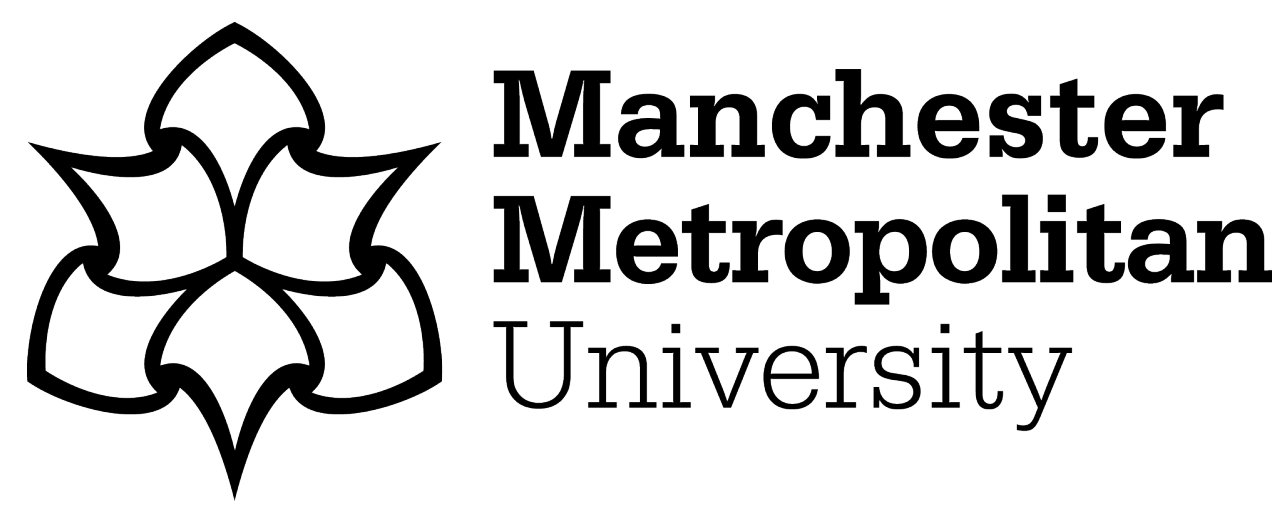

Vafadarnikjoo, A ORCID logoORCID: https://orcid.org/0000-0003-21476043, Tavana, M, Botelho, T and Chalvatzis, K (2020) A neutrosophic enhanced best-worst method for considering decision-makers' confidence in the best and worst criteria. Annals of Operations Research, 289. pp. 391418. ISSN 0254-5330

Downloaded from: https://e-space.mmu.ac.uk/627683/

Version: Accepted Version

Publisher: Springer (part of Springer Nature)

DOI: https://doi.org/10.1007/s10479-020-03603-x

Please cite the published version 


\title{
A Neutrosophic Enhanced Best-Worst Method for Considering Decision-Makers' \\ Confidence in the Best and Worst Criteria
}

\author{
Amin Vafadarnikjoo

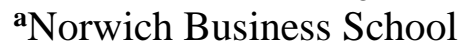 \\ University of East Anglia, United Kingdom \\ Madjid Tavana ${ }^{b, c, *}$ \\ ${ }^{\mathbf{b}}$ Business Systems and Analytics Department \\ Distinguished Chair of Business Systems and Analytics \\ La Salle University, Philadelphia, PA 19141, USA \\ E-mail: tavana@lasalle.edu \\ Web: http://tavana.us/ \\ 'Business Information Systems Department \\ Faculty of Business Administration and Economics \\ University of Paderborn, D-33098 Paderborn, Germany \\ Tiago Botelho ${ }^{\text {a }}$ \\ aNorwich Business School \\ University of East Anglia, United Kingdom \\ E-mail: T.Dos-Santos-Botelho@uea.ac.uk \\ Konstantinos Chalvatzis ${ }^{\text {a,d }}$ \\ ${ }^{a}$ Norwich Business School \\ University of East Anglia, United Kingdom \\ E-mail: k.chalvatzis@uea.ac.uk \\ dTyndall Centre for Climate Change Research \\ University of East Anglia, United Kingdom
}

DOI: https://doi.org/10.1007/s10479-020-03603-x

${ }^{*}$ Corresponding author at: Business Systems and Analytics Department, Distinguished Chair of Business Analytics, La Salle University, Philadelphia, PA 19141, United States. Tel.: +1 2159511129. 


\title{
A Neutrosophic Enhanced Best-Worst Method for Considering Decision-Makers' Confidence in the Best and Worst Criteria
}

\begin{abstract}
The best-worst method (BWM) is a multiple criteria decision-making (MCDM) method for evaluating a set of alternatives based on a set of decision criteria where two vectors of pairwise comparisons are used to calculate the importance weight of decision criteria. The BWM is an efficient and mathematically sound method used to solve a wide range of MCDM problems by reducing the number of pairwise comparisons and identifying the inconsistencies derived from the comparison process. In spite of its simplicity and efficiency, the BWM does not consider the decision-makers' (DMs') confidence in their pairwise comparisons. We propose a neutrosophic enhancement to the original BWM by introducing two new parameters as the DMs' confidence in the best-to-others preferences and the DMs' confidence in the others-to-worst preferences. We present two real-world cases to illustrate the applicability of the proposed neutrosophic enhanced BWM (NE-BWM) by considering confidence rating levels of the DMs.
\end{abstract}

Keywords: decision analysis; multiple criteria decision-making; best-worst method; neutrosophic sets; pairwise comparisons. 


\section{Introduction}

Multiple attribute decision-making (MADM) methods are developed to select a suitable alternative from a pre-defined discrete set of alternative courses of action. As it is commonly seen in the literature, the terms MADM, multiple criteria decision-making (MCDM), or multiple criteria decision analysis (MCDA) are often used interchangeably (Govindan and Jepsen, 2016). MCDM methods aim at selecting a suitable course of action, choice, policy, or strategy in decision problems with multiple and often conflicting qualitative and/or quantitative criteria under certainty or uncertainty (Kumar, 2010; Kuo, 2017). The main goal in MADM is to provide several attribute aggregation methods that make model development possible based on decision-makers' (DMs') or subject experts' preferential system and judgment policy (Doumpos and Zopounidis, 2002; Tavana and Hatami-Marbini, 2011). The number of published applications of MADM has grown rapidly over the last two decades (Huang et al., 2011; Marttunen et al., 2017), considering a large number of available MADM methods (Mulliner et al., 2013, 2016).

The best-worst method (BWM), proposed by Rezaei (2015), is a relatively new method that has successfully attracted researchers' attention from various fields since its introduction. The simplicity of use, the smaller number of pairwise comparisons, and more consistent comparisons compared to similar methods like the analytic hierarchy process (AHP), have made the BWM a reliable and popular method. The BWM can help DMs in determining the weights of criteria by identifying the best (i.e., most favorable or most important) and the worst (i.e., least favorable or least important) criteria. Pairwise comparisons are then carried out between each of the two criteria (i.e., best and worst) and other criteria. Next, the weights of criteria are determined by solving a minimax problem. Although the rankings in BWM are shown to be reasonable, they can be improved to capture the DMs' doubtfulness. In the original BWM, two vectors of pairwise 
comparisons (best-to-others and others-to-worst vectors) are considered equally important. The first vector (i.e., best to others) is called Separation $I$, and the second vector (i.e., others-to-worst) is called Separation II. In the original BWM, the degree of a DM's confidence in the best-toothers and others-to-worst preferences are considered equally important. The original BWM assumes a DM is fully confident about the most and least favorable criteria. The original BWM requires DMs to provide their best and worst criteria and the corresponding pairwise comparisons but does not consider the DMs' doubt over the separations $I$ and $I I$. In real-world problems, there are often situations where the DMs' have more confidence in their evaluations on one separation rather than the other. For example, the DMs might identify their best criterion confidently and provide the relevant pairwise comparisons but hesitate in choosing the worst criterion and its corresponding pairwise comparisons. This situation necessitates the introduction of two distinct uncertainty values.

Additionally, human judgments are biased by linguistic imprecision and vagueness; thus, to improve the outcome validity of the original BWM in real-world decision-making problems, the integration of uncertainty over separations $I$ and $I I$ into the original BWM can be beneficial to practicing managers. This concern motivated us to improve the effectiveness of the original BWM in the real-world problems by introducing $\rho^{+}$and $\rho^{-}$, the DM's confidence in the best-toothers preferences (the degree of certainty in separation $I$ ) and the DM's confidence in others-toworst preferences (the degree of certainty in separation $I I$ ), respectively. The $\rho^{+}$and $\rho^{-}$values represent the degree of DM's doubtfulness about which criterion is the best and which one is the worst. This uncertainty can be extended to pairwise comparisons and affect the confidence degree in separations $I$ and $I I$. Note that, in the original BWM, the two separations values are considered as being equal to 1 (i.e., $\rho^{+}=1$ and $\rho^{-}=1$ ). 
Dong et al. (2019) investigated the incomplete preference relations and self-confident preference relations in MCDM and realized that using self-confident preference relations instead of incomplete preference relations improves the quality of decision-making. This finding confirms the importance of capturing the confidence level of DMs in a decision-making method like the BWM. Furthermore, a recent survey of the BWM literature (Mi et al., 2019) suggests that scholars should focus on the uncertainty extension of the original BWM as a predominant research direction. We follow these suggestions by addressing the gap in the literature by proposing a DM's uncertain confidence in the best-to-others preferences $\left(\rho^{+}\right)$and others-to-worst preferences $\left(\rho^{-}\right)$ in the BWM. The main contribution of this study is to enhance the original BWM in the presence of DMs' doubt about the two vectors of best-to-others and others-to-worst preferences. The original BWM assumes a DM is fully confident in the most and least favorable criteria, which may not be true in all decision-making problems. This shortcoming motivated us to enhance the original BWM by proposing the neutrosophic enhanced BWM (NE-BWM), which considers neutrosophic set theory (NST) to structure a DM's uncertainty in terms of $\rho^{+}$and $\rho^{-}$values (the concept and mathematical definitions of NST are described in Appendix A). We also present two real-world cases to demonstrate the applicability and efficacy of the proposed method. The results are analyzed in 21 test problems under various $\rho^{+}$and $\rho^{-}$values based on a partial factorial experiment. In addition, a new output measurement index, namely, confidence difference $(C D)$ for the NE-BWM, is proposed and elaborated. Finally, the results are compared with the original BWM, and some findings are discussed.

The remainder of the paper is organized as follows. In Section 2, we review the literature on the BWM and the uncertainty concept. The details of the proposed NE-BWM is provided in Section 3. In Section 4, we present two real-world applications of the NE-BWM followed by the 
results of the case studies in Section 5. In Section 6, we present our conclusions and future research directions.

\section{Literature Review}

\subsection{The best-worst method}

The BWM functions similar to the AHP as both methods use pairwise comparisons, but the BWM benefits from some advantages over the AHP, which has made it more popular in recent years. One merit is the BWM's requirement of fewer comparisons than those that are required in the AHP. Secondly, the BWM consists of a lower complexity of comparisons as in the BWM, only whole numbers (i.e., 1-9 scale) are utilized, while in the AHP, fractional numbers are also used (i.e., 1/9-9 scale). Using whole numbers makes the evaluation process and interpretations much easier since they can more easily be measured by human perception and cognition. Thirdly, the BWM properly maintains the consistency of pairwise comparisons because the redundant comparisons are eliminated. This means that the derived BWM's results are more reliable than the ones obtained by the AHP (Mi et al., 2019).

The BWM has been successfully used in a wide range of studies. Some of the recent applications of the BWM include measuring project provider performance (Asadabadi et al. 2020); third-party logistics (Pamucar et al., 2019); renewable energy integration (Vishnupriyan and Manoharan, 2018); power plants alternatives selection (Omrani et al., 2018); battery energy storage systems (Zhao et al., 2018); financial performance analysis (Alimohammadlou and Bonyani, 2018); sustainable architecture (Amoozad Mahdiraji et al., 2018); acute leukemia classification (Alsalem et al., 2018), and sustainable supplier selection in the plastics industry (Cheraghalipour and Farsad, 2018).

Huge efforts have been made to develop the BWM theoretically and integrate it with other 
techniques. Mi et al. (2019) recently reviewed the BWM literature providing insightful, detailed information on the BWM theoretical extensions and practical applications. They have indicated that $67 \%$ of the BWM publications are related to the integration of the BWM. Almost half of this amount focused on the singleton integrations of the BWM, while the rest integrated more than one method with the BWM. The most popular singleton integrations of the BWM include uncertainty (i.e., fuzzy information), TOPSIS ${ }^{1}$, VIKOR ${ }^{2}$, and $\mathrm{FDM}^{3}$.

A recent list of the BWM integrations include the integrated DEA ${ }^{4}$ and BWM (Omrani et al., 2020); the Euclidean BWM (Kocak et al., 2018); the PHFE ${ }^{5}$ and the BWM (Li et al., 2019); the Z-number extension of the BWM (Aboutorab et al., 2018); the mixed grey-based BWM and TODIM $^{6}$ (Bai et al., 2019); the hybrid fuzzy BWM and COPRAS ${ }^{7}$ method (Amoozad Mahdiraji et al., 2018); the integrated BWM and VIKOR method (Cheraghalipour et al., 2018; Gupta, 2018a; Garg and Sharma, 2018); the hybrid fuzzy TOPSIS and the BWM (Gupta, 2018b; Gupta and Barua, 2018; Lo et al., 2018); the hybrid BWM and ELECTRE ${ }^{8}$ method (Yadav et al., 2018); the fuzzy BWM and fuzzy MULTIMOORA ${ }^{9}$ (Liu et al., 2018a); rough numbers and the BWM (i.e. RBWM) and VIKOR (Liu et al., 2018b); the integrated IRN ${ }^{10}$ and the BWM (IRN-BWM) (Pamucar et al., 2019); the MILM ${ }^{11}$ to provide better approximate solutions to the original NLM ${ }^{12}$ in the BWM (Beemsterboer et al., 2018); the fuzzy BWM (Guo and Zhao, 2017; Hafezalkotob and

\footnotetext{
${ }^{1}$ Technique for Order Preference by Similarity to Ideal Solution (TOPSIS)

${ }^{2}$ Vlsekriterijumska Optimizacija I Kompromisno Resenje (in Serbian) (VIKOR)

${ }^{3}$ Fuzzy-Delphi Method (FDM)

${ }^{4}$ Data Envelopment Analysis (DEA)

${ }^{5}$ Probabilistic Hesitant Fuzzy Elements (PHFE)

${ }^{6}$ TOmada de Deciso Interativa e Multicritrio (in Portuguese) (TODIM) meaning interactive and multicriteria decision-making

${ }^{7}$ COmplex PRoportional ASsessment (COPRAS)

${ }^{8}$ ELimination Et Choix Traduisant la REalit (in French) (ELECTRE) or elimination and choice expressing reality

${ }^{9}$ Multi-Objective Optimization by Ratio Analysis plus the full MULTIplicative form (MULTIMOORA)

${ }^{10}$ Interval Rough Number (IRN)

${ }^{11}$ Mixed Integer Linear Model (MILM)

${ }^{12}$ Non-Linear Model (NLM)
} 
Hafezalkotob, 2017; Maghsoodi et al., 2019); the IF-BWM ${ }^{13}$ (Mou et al., 2017) and the IFMBWM $^{14}$ (Mou et al., 2016).

\subsection{Uncertainty concept}

Uncertainty in MADM is not a new theme but a largely developing topic, which has evolved in close connection with uncertainty theories such as fuzzy sets or grey systems that have their roots in mathematics. Booker and Ross (2011) stated that uncertainty could be defined as what is not known precisely, though, Zimmermann (2000) indicated that he had not been successful in finding any general definition for uncertainty. Since the introduction of fuzzy sets by Zadeh (1965), probability theory was challenged, as it had been the sole representation of uncertainty. Subsequently, developments in mathematical uncertainty theories have been proposed such as the possibility theory in 1988 (see Dubois and Prade (2012)); Dempster-Shafer evidence theory that has been developed by Dempster (1968) and then by Shafer (1976) to model belief or evidence (Kämpke, 1988); imprecise probability theory (Walley, 1991) and random intervals (Joslyn and Booker, 2004). Smarandache (1999) introduced a non-classical logic, which has roots in philosophy (Smarandache, 2002) as an alternative to the existing logical systems, namely neutrosophic logic, to represent a mathematical model of uncertainty. Smarandache (1999) proposed neutrosophic sets (NSs) that show fuzzy information utilizing the functions of truth, indeterminacy, and falsity like intuitionistic fuzzy sets (IFSs). Atanassov (1986) introduced IFS as an extension of the well-known fuzzy set theory of Zadeh (Zadeh, 1965) to overcome its drawbacks by providing the concept of non-membership degree (Govindan et al., 2015). The distinction between NSs and IFSs is that the function of indeterminacy in NSs is independent of the truth and falsity functions (Ji et al., 2018). Smarandache generalized the IFS into the NS to show insights

\footnotetext{
${ }^{13}$ Intuitionistic Fuzzy BWM (IF-BWM)

${ }^{14}$ Intuitionistic Fuzzy Multiplicative BWM (IFM-BWM)
} 
on how a more efficient DM handles uncertainty using subjective judgments (see Appendix A). Levary and Wan (1998) indicated that there are two types of uncertainties; first, uncertainty related to the prospective traits of the decision-making environment characterized by a set of scenarios; and second, uncertainty regarding the decision-making judgment associated with pairwise comparisons. This research deals with the second type of uncertainty.

In the related literature, apart from uncertainty theories, various decision support tools have been proposed to handle uncertainty in decision-making, such as the work of Baudry et al. (2018) that proposed a new framework to support participatory decision-making under uncertainty namely, the range-based multi-actor, multi-criteria analysis. This trend reinforces the importance of decision-making under uncertainty, where the focus is to produce reliable solutions for complex real-world problems. Temur (2016) emphasized this growing trend in the integration of uncertainty theories with MADM methods in handling uncertainty.

In several MADM methods like the AHP and the BWM, it is necessary to acquire experts' opinions in pairwise comparisons of alternatives and criteria. And as there are linguistic imprecision and vagueness in human judgment, it would be essential to apply an uncertainty theory to deal with imprecision. Each one of the uncertainty theories has unique characteristics (Yamaguchi et al., 2007). Reflecting on the drawbacks of each uncertainty theory has led to the introduction of new theories, such as the NST from mathematics, into the decision-making sphere, and applying the newly developed hybrid MADM methodologies under uncertainty. In this study, we take advantage of using the NST in structuring the value assignment process in terms of $\rho^{+}$ and $\rho^{-}$values while dealing with DMs' uncertainty in the enhanced BWM. The NST provides a rating scale for DMs to express their level of confidence in terms of $\rho^{+}$and $\rho^{-}$values. Lacking such a theory, the proposed enhanced BWM would not be able to structure the confidence value 
acquisitions, and thus, the DMs would find it difficult to express their confidence. The reasons to choose the NST out of other uncertainty theories are summarized as follows:

- As indicated in Section 2.1, fuzzy information and the fuzzy set theory (FST) has been used in conjunction with the original BWM. Even though fuzzy set information proved to be very handy, it is unable to express the information about rejection (Ashraf et al., 2019), which is effectively quantified in the NST by introducing the falsity-membership function.

- The NST can quantify the indeterminacy membership independently, which adds an extra level of suitability to it for structuring DMs' confidence level.

\section{The Proposed Neutrosophic Enhanced BWM (NE-BWM)}

The original BWM is described in Rezaei $(2015,2016)$ which follows a five-step approach; the proposed NE-BWM has two additional steps, which are explained as follows:

\section{Step 1. Decision criteria}

A set of decision criteria $(N)$ should be established to make a decision and do the analysis, as shown in Equation (1).

$$
N=\left\{C_{1}, C_{2}, \ldots, C_{n}\right\}
$$

\section{Step 2. The best and worst criteria}

A DM determines the best criterion (i.e., the most favorable one) and the worst criterion (i.e. the least favorable one).

\section{Step 3. Best-to-others vector}

As shown in Table 1, a DM expresses their preference of the best criterion over all other criteria using a scale from 1 to 9 (Ishizaka, 2012; Rezaei, 2015; Saaty, 1977, 2005). The resulting vector is represented by $A_{B}=\left(a_{B 1}, a_{B 2}, \ldots, a_{B n}\right)$ where $a_{B j}$ signifies the preference of the best criterion $B$ over criterion $j$. It is also obvious that $a_{B B}=1$. 
Table 1. The importance of rating scale

\begin{tabular}{|c|c|}
\hline Numerical scale & Verbal scale \\
\hline 1 & Equally important \\
\hline 2 & Weakly more important \\
\hline 3 & Moderately more important \\
\hline 4 & Moderately Plus more important \\
\hline 5 & Strongly more important \\
\hline 6 & Strongly Plus more important \\
\hline 7 & Very Strongly Plus more important \\
\hline 8 & Very Very Strongly more important \\
\hline 9 & Extremely more important \\
\hline
\end{tabular}

Step 4. Others-to-worst vector

A DM determines the preference of all criteria over the worst criterion using a scale from 1 to 9

(Table 1). The resulting vector is represented by $A_{W}=\left(a_{1 W}, a_{2 W}, \ldots, a_{n W}\right)$ where $a_{j W}$ indicates the preference of the criterion $j$ over the worst criterion $W$. Clearly, $a_{W W}=1$.

The following two steps are uniquely enhanced and introduced for the proposed NE-BWM:

Step 5. DM's uncertain confidence in the best-to-others preferences

A DM is asked to provide his/her confidence in the best-to-others preferences, which would inherently include the uncertainty of their choice in the best criterion. Note that a DM is required to indicate his/her confidence using linguistic phrases presented in Table 2. Appendix B-Q1 presents a sample question used to acquire a DM's uncertainty in his/her best-to-others preferences. The neutrosophic value of the DM's confidence on the best-to-others preferences $\left(\rho^{+}\right)$is represented as a single-valued trapezoidal neutrosophic number (SVTNN) (see Definition A.3 in Appendix A), which is then substituted for the provided verbal term (Table 2). It reveals the degree of DM's confidence in Separation $I$. The crisp values in Table 2 are calculated based on Equation (A.6). 
Table 2. The confidence rating scale

\begin{tabular}{|l|c|c|c|}
\hline \multicolumn{1}{|c|}{ Linguistic Phrase } & Score & \multicolumn{1}{c|}{ SVTNN } & Crisp Value \\
\hline No Confidence & 0 & $\langle(0.0,0.0,0.0,0.0), 0.0,0.0,0.0\rangle$ & 0.00 \\
\hline Low Confidence & 1 & $\langle(0.2,0.3,0.4,0.5), 0.6,0.2,0.2\rangle$ & 0.26 \\
\hline Fairly Low Confidence & 2 & $\langle(0.3,0.4,0.5,0.6), 0.7,0.1,0.1\rangle$ & 0.38 \\
\hline Medium Confidence & 3 & $\langle(0.4,0.5,0.6,0.7), 0.8,0.0,0.1\rangle$ & 0.50 \\
\hline Fairly High Confidence & 4 & $\langle(0.7,0.8,0.9,1.0), 0.8,0.2,0.2\rangle$ & 0.68 \\
\hline High Confidence & 5 & $\langle(1.0,1.0,1.0,1.0), 0.9,0.1,0.1\rangle$ & 0.90 \\
\hline Absolutely High Confidence & 6 & $\langle(1.0,1.0,1.0,1.0), 1.0,0.0,0.0\rangle$ & 1.00 \\
\hline
\end{tabular}

Step 6. DM's uncertain confidence in others-to-worst preferences

A DM is asked to provide his/her confidence in their others-to-worst preferences, which inherently include the uncertainty of their choice on the worst criterion. Note that a DM is required to indicate his/her confidence using linguistic phrases as represented in Table 2. Appendix B-Q2 presents a sample question used to acquire the DM's uncertainty on others-to-worst preferences. The neutrosophic value of the DM's confidence on the others-to-worst preferences $\left(\rho^{-}\right)$is a SVTNN, which is then substituted for the verbal term (Table 2). It reveals the degree of DM's confidence in Separation II .

\section{Step 7. Optimal weights}

Model (2) was proposed in the original non-linear BWM and then transformed to Model (3), which provides the optimal weights (Rezaei, 2015). The proposed Model (4) can be established by applying $\rho^{+}$and $\rho^{-}$in the objective function of Model (2).

$$
\min \max _{j}\left\{\left|\frac{W_{B}}{W_{j}}-a_{B j}\right|,\left|\frac{W_{j}}{W_{W}}-a_{j W}\right|\right\}
$$

s.t.

$$
\sum_{j} W_{j}=1
$$


$W_{j} \geq 0$

$\forall j \in N$

where $N$ is the set of all criteria.

$\min \varepsilon$

s.t.

$\left|\frac{W_{B}}{W_{j}}-a_{B j}\right| \leq \varepsilon$

$\forall j \in N$

$\left|\frac{W_{j}}{W_{W}}-a_{j W}\right| \leq \varepsilon$

$\forall j \in N$

$\sum_{j} W_{j}=1$

$W_{j} \geq 0$

$\forall j \in N$

$\min \max _{j}\left\{\rho^{+}\left|\frac{W_{B}}{W_{j}}-a_{B j}\right|, \rho^{-}\left|\frac{W_{j}}{W_{W}}-a_{j W}\right|\right\}$

s.t.

$$
\begin{aligned}
& \sum_{j} W_{j}=1 \\
& W_{j} \geq 0 ; \forall j \in N
\end{aligned}
$$

where $0<\rho^{+} \leq 1$ and $0<\rho^{-} \leq 1$.

Model (4) is then transformed into Models (5) and (6).

$\min \left\{\frac{\varepsilon}{\rho^{+}}+\frac{\varepsilon}{\rho^{-}}\right\}$

s.t. 
$\left|\frac{W_{B}}{W_{j}}-a_{B j}\right| \leq \frac{\varepsilon}{\rho^{+}}$

$\forall j \in N$

$\left|\frac{W_{j}}{W_{W}}-a_{j W}\right| \leq \frac{\varepsilon}{\rho^{-}}$

$\forall j \in N$

$\sum_{j} W_{j}=1$

$W_{j} \geq 0$

$\forall j \in N$

Finally, by solving Model (6), the criteria weights are obtained.

$\min \varepsilon\left(\frac{\rho^{-}+\rho^{+}}{\rho^{-} \rho^{+}}\right)$

s.t.

$\frac{W_{B}}{W_{j}}-\frac{\varepsilon}{\rho^{+}} \leq a_{B j} \quad \forall j \in N$

$\frac{W_{B}}{W_{j}}+\frac{\varepsilon}{\rho^{+}} \geq a_{B j} \quad \forall j \in N$

$\frac{W_{j}}{W_{W}}-\frac{\varepsilon}{\rho^{-}} \leq a_{j W} \quad \forall j \in N$

$\frac{W_{j}}{W_{W}}+\frac{\varepsilon}{\rho^{-}} \geq a_{j W} \quad \forall j \in N$

$\sum_{j} W_{j}=1$

$W_{j} \geq 0 \quad \forall j \in N$

\subsection{Consistency ratio}

The CR, which is the cardinal and output-based consistency for the proposed NE-BWM, is described in this section. The lower the CR, the higher the consistency of evaluations. Liang et al. 
(2019) introduced CR thresholds based on the number of criteria and maximum grade values.

Given $a_{B W}$ is the preference of the best criterion over the worst criterion, then a comparison is fully consistent when $a_{B j} \times a_{j W}=a_{B W}$. The minimum consistency of comparison is calculated as follows:

Consider $a_{i j} \in\left\{1, \ldots, a_{B W}\right\}$ and that the highest possible value of $a_{B W}$ is 9. Consistency decreases when $a_{B j} \times a_{j W} \neq a_{B W}$ and the highest inequality occurs when $a_{B j}=a_{j W}=a_{B W}$. Given the highest inequality as a result of assigning the maximum value by $a_{B j}$ and $a_{j W}$ then, Model (6) can be used to calculate the consistency ratio based on Equation (7).

$\left(a_{B j}-\frac{\varepsilon}{\rho^{+}}\right) \times\left(a_{j W}-\frac{\varepsilon}{\rho^{-}}\right)=\left(a_{B W}+\varepsilon\left(\frac{\rho^{-}+\rho^{+}}{\rho^{-} \rho^{+}}\right)\right)$

As for the minimum consistency, $a_{B j}=a_{j W}=a_{B W}$, we can then obtain Equation (8).

$$
\left(a_{B W}-\frac{\varepsilon}{\rho^{+}}\right) \times\left(a_{B W}-\frac{\varepsilon}{\rho^{-}}\right)=\left(a_{B W}+\varepsilon\left(\frac{\rho^{-}+\rho^{+}}{\rho^{-} \rho^{+}}\right)\right)
$$

Based on Equation (8), Equation (9) can then be obtained.

$$
\begin{aligned}
& \left(\frac{1}{\rho^{+} \rho^{-}}\right) \varepsilon^{2}-\left(\frac{a_{B W}\left(\rho^{+}+\rho^{-}\right)+\rho^{+}+\rho^{-}}{\rho^{+} \rho^{-}}\right) \varepsilon+\left(a_{B W}^{2}-a_{B W}\right)=0 \\
& a_{B W} \quad \text { can take on values }\{1, \ldots, 9\} \quad(\text { Table } 1) \text { and based on Table } 2,
\end{aligned}
$$
$\rho^{+} \in\{0.26,0.38,0.50,0.68,0.90,1.00\}$ and $\rho^{-}=\{0.26,0.38,0.50,0.68,0.90,1.00\}$. We assume that $\rho^{+}$and $\rho^{-}$could not be 0 , as the evaluation of a DM with no confidence in their opinion could be easily dismissed. The maximum possible value of $\varepsilon$ can be calculated by solving Equation (9). The obtained values are recognized as the consistency index ( $C I)$ values and are represented in Appendix C. After solving Model (6), the $\varepsilon^{*}$ is obtained, and then the $C R$ can be calculated by 
Equation (10).

$$
C R=\frac{\varepsilon^{*}}{C I}
$$

\subsection{Confidence difference}

The $C D$ is proposed to measure the output of the NE-BWM. It is the difference between the confidence degree of separations $I$ and $I I$ as shown in Equation (11).

$$
C D=\left|\rho^{+}-\rho^{-}\right|
$$

\section{Case studies}

The supply chain is a popular application area for the BWM in the literature (Mi et al., 2019). Thus, in the current study, real-world applications in two supply chain cases are conducted to verify the applicability of the proposed NE-BWM. In both cases, we chose 21 test problems based on Table 2 and calculated the $C I$ values for them, as shown in Appendix C.

\subsection{Parameter setting}

A partial factorial experiment has been conducted to obtain the 21 test problems, including 1 original BWM test problem and 20 NE-BWM test problems based on various DM's confidence levels (Table 2). As mentioned earlier, based on Table 2, $\rho^{+} \in\{0.26,0.38,0.50,0.68,0.90,1.00\}$ and $\rho^{-}=\{0.26,0.38,0.50,0.68,0.90,1.00\}$ can make 36 possible total combinations that out of which 21 combinations are chosen. The obtained 20 test problems in NE-BWM are chosen because they provide all unique possible $C I$ values (Appendix C). In Figure 1, all 20 combinations in NE-BWM analysis are depicted as represented in Tables 5 and 9 (test problems 2 to 21). In one outcome out of 21, the NE-BWM problem is equal to the original BWM problem where the DM is fully confident (i.e., $\rho^{+}=1$ and $\rho^{-}=1$ ), and obviously, zero confidence shall not be taken into consideration. 


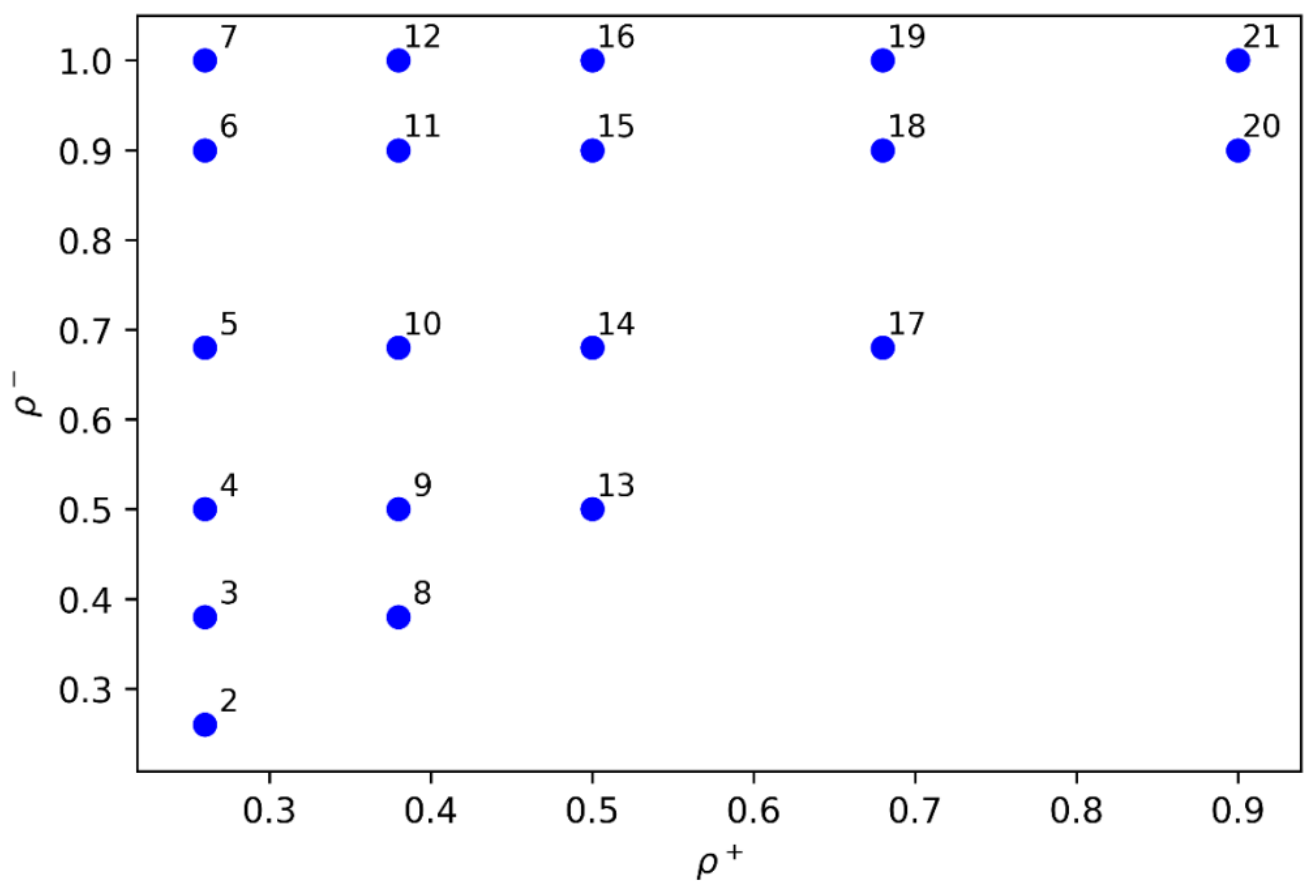

Figure 1. The obtained 20 test problems ( 2 to 21 in Tables 5 and 9)

\subsection{Case 1: A supplier development problem}

Rezaei et al. (2015) discussed the supplier development problem applying the BWM to evaluate eight identified supplier capability criteria and to obtain their weights. The eight criteria included supplier capability $\left(C_{1}^{c}\right)$, product quality capability $\left(C_{2}^{c}\right)$, delivery capability $\left(C_{3}^{c}\right)$, intangible capability $\left(C_{4}^{c}\right)$, service capability $\left(C_{5}^{c}\right)$, financial/cost capability $\left(C_{6}^{c}\right)$, sustainable capability $\left(C_{7}^{c}\right)$, and organizational capability $\left(C_{8}^{c}\right)$. Here, the BWM evaluation data (Tables 3 and 4) are utilized to compare the results of the original BWM and the proposed NE-BWM in a real-case application. The best capability criterion is product quality capability $\left(C_{2}^{c}\right)$, and the worst capability criterion is the organizational capability $\left(C_{8}^{c}\right)$ and $a_{B W}=9$. Based on the $C I$ table in Rezaei (2015), the $C R$ for the original BWM would be $C R=\frac{0.8599}{5.23}=0.1644$, the acceptable threshold proposed by Liang et al. (2019) for this problem is 0.4587 which indicates the pairwise 
comparisons are cardinally consistent based on output-based consistency measurement.

Table 3. Best-to-others vector (Case 1)

\begin{tabular}{|l|c|c|c|c|c|c|c|c|}
\hline Criteria & $C_{1}^{c}$ & $C_{2}^{c}$ & $C_{3}^{c}$ & $C_{4}^{c}$ & $C_{5}^{c}$ & $C_{6}^{c}$ & $C_{7}^{c}$ & $C_{8}^{c}$ \\
\hline The Best Criterion $\left(C_{2}^{c}\right)$ & 6 & 1 & 2 & 8 & 5 & 3 & 4 & 9 \\
\hline
\end{tabular}

Table 4. Others-to-worst vector (Case 1)

\begin{tabular}{|c|c|}
\hline Criteria & $\begin{array}{c}\text { Worst } \\
\text { Criterion }\left(C_{8}^{c}\right)\end{array}$ \\
\hline$C_{1}^{c}$ & 2 \\
\hline$C_{2}^{c}$ & 9 \\
\hline$C_{3}^{c}$ & 8 \\
\hline$C_{4}^{c}$ & 2 \\
\hline$C_{5}^{c}$ & 3 \\
\hline$C_{6}^{c}$ & 5 \\
\hline$C_{7}^{c}$ & 4 \\
\hline$C_{8}^{c}$ & 1 \\
\hline
\end{tabular}

In Table 5, the analysis of all test problems in Case 1 is provided for the original and the NE-BWM, considering various $\rho^{+}$and $\rho^{-}$. The calculated weights of all criteria, along with their new rankings, objective function value $\left(\varepsilon^{*}\right)$, and $C R$ are presented in Table 5.

Table 5. Analysis of 21 test problems in Case 1

\begin{tabular}{|c|c|c|c|c|c|c|c|c|c|c|c|}
\hline \multicolumn{12}{|c|}{ Original BWM } \\
\hline \multirow{2}{*}{$N^{\circ}$} & & $W_{1}^{*}$ & $W_{2}^{*}$ & $W_{3}^{*}$ & $W_{4}^{*}$ & $W_{5}^{*}$ & $W_{6}^{*}$ & $W_{7}^{*}$ & $W_{8}^{*}$ & $\varepsilon^{*}$ & $C R$ \\
\hline & & 0.0532 & 0.3093 & 0.2713 & 0.0393 & 0.0671 & 0.1299 & 0.0985 & 0.0314 & 0.8599 & 0.1644 \\
\hline 1 & ranking $(0)$ & 6 & 1 & 2 & 7 & 5 & 3 & 4 & 8 & - & - \\
\hline \multicolumn{12}{|c|}{ NE-BWM } \\
\hline & & $W_{1}^{*}$ & $W_{2}^{*}$ & $W_{3}^{*}$ & $W_{4}^{*}$ & $W_{5}^{*}$ & $W_{6}^{*}$ & $W_{7}^{*}$ & $W_{8}^{*}$ & $\varepsilon^{*}$ & $C R$ \\
\hline \multirow{3}{*}{2} & $\rho^{+}=0.26$ & \multirow{2}{*}{0.0624} & \multirow{2}{*}{0.3210} & \multirow{2}{*}{0.2324} & \multirow{2}{*}{0.0371} & \multirow{2}{*}{0.0775} & \multirow{2}{*}{0.1348} & \multirow{2}{*}{0.1022} & \multirow{2}{*}{0.0325} & \multirow{2}{*}{0.2236} & \multirow{2}{*}{0.1827} \\
\hline & $\rho^{-}=0.26$ & & & & & & & & & & \\
\hline & ranking $(0)$ & 6 & 1 & 2 & 7 & 5 & 3 & 4 & 8 & - & - \\
\hline \multirow{3}{*}{3} & $\rho^{+}=0.26$ & \multirow{2}{*}{0.0566} & \multirow{2}{*}{0.3125} & \multirow{2}{*}{0.2344} & \multirow{2}{*}{0.0417} & \multirow{2}{*}{0.0790} & \multirow{2}{*}{0.1379} & \multirow{2}{*}{0.1057} & \multirow{2}{*}{0.0322} & \multirow{2}{*}{0.2714} & \multirow{2}{*}{0.1895} \\
\hline & $\rho^{-}=0.38$ & & & & & & & & & & \\
\hline & ranking $(0)$ & 6 & 1 & 2 & 7 & 5 & 3 & 4 & 8 & - & - \\
\hline \multirow{3}{*}{4} & $\rho^{+}=0.26$ & \multirow{2}{*}{0.0438} & \multirow{2}{*}{0.3018} & \multirow{2}{*}{0.2323} & \multirow{2}{*}{0.0442} & \multirow{2}{*}{0.0752} & \multirow{2}{*}{0.1648} & \multirow{2}{*}{0.1066} & \multirow{2}{*}{0.0314} & \multirow{2}{*}{0.3037} & \multirow{2}{*}{0.1964} \\
\hline & $\rho^{-}=0.50$ & & & & & & & & & & \\
\hline & ranking (1) & 7 & 1 & 2 & 6 & 5 & 3 & 4 & 8 & - & - \\
\hline
\end{tabular}




\begin{tabular}{|c|c|c|c|c|c|c|c|c|c|c|c|}
\hline \multirow{3}{*}{5} & $\rho^{+}=0.26$ & \multirow{2}{*}{0.0648} & \multirow{2}{*}{0.2989} & \multirow{2}{*}{0.2333} & \multirow{2}{*}{0.0455} & \multirow{2}{*}{0.0786} & \multirow{2}{*}{0.1394} & \multirow{2}{*}{0.1081} & \multirow{2}{*}{0.0313} & \multirow{2}{*}{0.3719} & \multirow{2}{*}{0.2266} \\
\hline & $\rho^{-}=0.68$ & & & & & & & & & & \\
\hline & ranking $(0)$ & 6 & 1 & 2 & 7 & 5 & 3 & 4 & 8 & - & - \\
\hline \multirow{3}{*}{6} & $\rho^{+}=0.26$ & \multirow{2}{*}{0.0659} & \multirow{2}{*}{0.2832} & \multirow{2}{*}{0.2534} & \multirow{2}{*}{0.0450} & \multirow{2}{*}{0.0748} & \multirow{2}{*}{0.1431} & \multirow{2}{*}{0.1047} & \multirow{2}{*}{0.0298} & \multirow{2}{*}{0.4431} & \multirow{2}{*}{0.2603} \\
\hline & $\rho^{-}=0.90$ & & & & & & & & & & \\
\hline & ranking (0) & 6 & 1 & 2 & 7 & 5 & 3 & 4 & 8 & - & - \\
\hline \multirow{3}{*}{7} & $\rho^{+}=0.26$ & \multirow{2}{*}{0.0521} & م 000 & 02505 & 00167 & & & & & & \\
\hline & $\rho^{-}=1.00$ & & 0.2890 & 0.2585 & $0.040 /$ & $0.07 / 2$ & 0.1382 & $0.10 / 8$ & 0.0305 & $0.4 / 03$ & 0.2133 \\
\hline & ranking $(0)$ & 6 & 1 & 2 & 7 & 5 & 3 & 4 & 8 & - & - \\
\hline & $\rho^{+}=0.38$ & & & & & & & & & & \\
\hline 8 & $\rho^{-}=0.38$ & 0.0591 & 0.3038 & 0.2665 & 0.0351 & 0.0659 & 0.1420 & 0.0968 & 0.0308 & 0.3268 & 0.1827 \\
\hline & ranking $(0)$ & 6 & 1 & 2 & 7 & 5 & 3 & 4 & 8 & - & - \\
\hline & $\rho^{+}=0.38$ & & & & & & & & & & \\
\hline 9 & $\rho^{-}=0.50$ & 0.0630 & 0.3154 & 0.2342 & 0.0402 & 0.0726 & $0.13 / 2$ & 0.1049 & 0.0323 & 0.3776 & 0.1872 \\
\hline & ranking $(0)$ & 6 & 1 & 2 & 7 & 5 & 3 & 4 & 8 & - & - \\
\hline & $\rho^{+}=0.38$ & & & & & & & & & & \\
\hline 10 & $\rho^{-}=0.68$ & 0.0589 & 0.2864 & 0.2566 & 0.0406 & 0.0741 & 0.1537 & 0.1000 & 0.0297 & 0.4319 & 0.1945 \\
\hline & ranking $(0)$ & 6 & 1 & 2 & 7 & 5 & 3 & 4 & 8 & - & - \\
\hline & $\rho^{+}=0.38$ & & & & & & & & & & \\
\hline 11 & $\rho^{-}=0.90$ & 0.0614 & 0.3002 & 0.2333 & 0.0450 & 0.0768 & 0.1392 & 0.1127 & 0.0314 & 0.5081 & 0.2155 \\
\hline & ranking (0) & 6 & 1 & 2 & 7 & 5 & 3 & 4 & 8 & - & - \\
\hline & $\rho^{+}=0.38$ & & & & & & & & & & \\
\hline 12 & $\rho^{-}=1.00$ & 0.0547 & 0.2902 & 0.2598 & 0.0442 & 0.0746 & 0.1354 & 0.1107 & 0.0304 & 0.5457 & 0.2274 \\
\hline & ranking $(0)$ & 6 & 1 & 2 & 7 & 5 & 3 & 4 & 8 & - & - \\
\hline & $\rho^{+}=0.50$ & $\rho^{\prime} \cap \Omega$ & 7000 & ברבת & 00005 & 00756 & 0124 & ( 109 & م & 04200 & 01027 \\
\hline 13 & $\rho^{-}=0.50$ & 0.0624 & 0.3201 & 0.2323 & 0.0395 & $0.0 / 56$ & 0.1349 & 0.1021 & 0.0325 & 0.4300 & 0.1821 \\
\hline & ranking (0) & 6 & 1 & 2 & 7 & 5 & 3 & 4 & 8 & - & - \\
\hline & $\rho^{+}=0.50$ & & & & & & & & & & \\
\hline 14 & $\rho^{-}=0.68$ & 0.0592 & 0.2953 & 0.2541 & 0.0416 & 0.0724 & 0.1484 & 0.0988 & 0.0303 & 0.5047 & 0.1879 \\
\hline & ranking $(0)$ & 6 & 1 & 2 & 7 & 5 & 3 & 4 & 8 & - & - \\
\hline & $\rho^{+}=0.50$ & & & & & & & & & & \\
\hline 15 & $\rho^{-}=0.90$ & 0.0581 & 0.2984 & 0.2282 & 0.0424 & 0.0773 & 0.1604 & 0.1043 & 0.0310 & 0.5696 & 0.1947 \\
\hline & ranking $(0)$ & 6 & 1 & 2 & 7 & 5 & 3 & 4 & 8 & - & - \\
\hline & $\rho^{+}=0.50$ & & & & & & & & & & \\
\hline 16 & $\rho^{-}=1.00$ & 0.0540 & 0.3063 & 0.2365 & 0.0449 & 0.0769 & 0.1407 & 0.1088 & 0.0319 & 0.5925 & 0.1975 \\
\hline & ranking $(0)$ & 6 & 1 & 2 & 7 & 5 & 3 & 4 & 8 & - & - \\
\hline & $\rho^{+}=0.68$ & & & & & & & & & & \\
\hline 17 & $\rho^{-}=0.68$ & 0.0609 & 0.3131 & 0.2365 & 0.0362 & 0.0756 & 0.1463 & 0.0997 & 0.0318 & 0.5848 & 0.1826 \\
\hline & ranking (0) & 6 & 1 & 2 & 7 & 5 & 3 & 4 & 8 & - & - \\
\hline
\end{tabular}




\begin{tabular}{|c|c|c|c|c|c|c|c|c|c|c|c|}
\hline \multirow{3}{*}{18} & $\rho^{+}=0.68$ & \multirow{2}{*}{0.0555} & \multirow{2}{*}{0.2929} & \multirow{2}{*}{0.2629} & \multirow{2}{*}{0.0418} & \multirow{2}{*}{0.0732} & \multirow{2}{*}{0.1462} & \multirow{2}{*}{0.0975} & \multirow{2}{*}{0.0300} & \multirow{2}{*}{0.6776} & \multirow{2}{*}{0.1873} \\
\hline & $\rho^{-}=0.90$ & & & & & & & & & & \\
\hline & ranking $(0)$ & 6 & 1 & 2 & 7 & 5 & 3 & 4 & 8 & - & - \\
\hline \multirow{3}{*}{19} & $\rho^{+}=0.68$ & \multirow{2}{*}{0.0537} & \multirow{2}{*}{0.3141} & \multirow{2}{*}{0.2357} & \multirow{2}{*}{0.0452} & \multirow{2}{*}{0.0740} & \multirow{2}{*}{0.1387} & \multirow{2}{*}{0.1063} & \multirow{2}{*}{0.0323} & \multirow{2}{*}{0.7117} & \multirow{2}{*}{0.1897} \\
\hline & $\rho^{-}=1.00$ & & & & & & & & & & \\
\hline & ranking $(0)$ & 6 & 1 & 2 & 7 & 5 & 3 & 4 & 8 & - & - \\
\hline \multirow{3}{*}{20} & $\rho^{+}=0.90$ & \multirow{2}{*}{0.0566} & \multirow{2}{*}{0.3021} & \multirow{2}{*}{0.2650} & \multirow{2}{*}{0.0422} & \multirow{2}{*}{0.0662} & \multirow{2}{*}{0.1411} & \multirow{2}{*}{0.0962} & \multirow{2}{*}{0.0306} & \multirow{2}{*}{0.7740} & \multirow{2}{*}{0.1826} \\
\hline & $\rho^{-}=0.90$ & & & & & & & & & & \\
\hline & ranking $(0)$ & 6 & 1 & 2 & 7 & 5 & 3 & 4 & 8 & - & - \\
\hline \multirow{3}{*}{21} & $\rho^{+}=0.90$ & \multirow{2}{*}{0.0564} & \multirow{2}{*}{0.3217} & \multirow{2}{*}{0.2352} & م0415 & 00714 & & & & & \\
\hline & $\rho^{-}=1.00$ & & & & 0.0415 & 0.0714 & 0.1509 & 0.1042 & $0.03<0$ & 0.8203 & 0.1841 \\
\hline & ranking $(0)$ & 6 & 1 & 2 & 7 & 5 & 3 & 4 & 8 & - & - \\
\hline
\end{tabular}

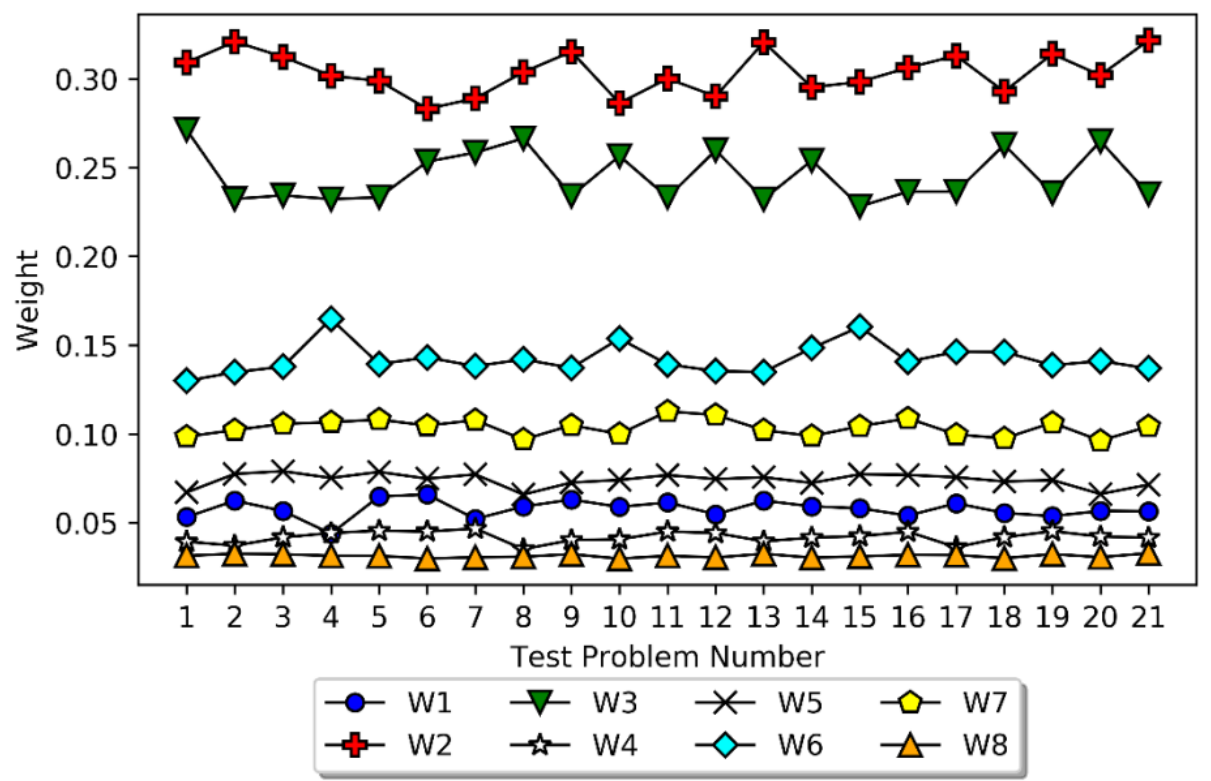

\section{Figure 2. Trend and ranking of weights in 21 test problems in Case 1}

The diagrams of weight changes for test problems in Case 1 are shown in Figure 2 based on the obtained weights in Table 5. In Case 1, no considerable changes in criteria weights have been observed after alterations in $\rho^{+}$and $\rho^{-}$(Figure 2). Only one new ranking (ranking 1) was observed in test problem 4 (Table 5 and Figure 2). The rest of the rankings remained the same as the original BWMs ranking (test problem 1 and ranking 0). In all the rankings $W_{2}$ (i.e., the weight of the best criterion $C_{2}^{c}$ ) is at the top and $W_{8}$ (weight of the worst criterion $C_{8}^{c}$ ) lies at the lowest 
part of the diagram (Figure 2).

Table 6. The NE-BWM weights analysis in Case 1

\begin{tabular}{|c|c|c|c|c|c|c|}
\hline Weights & $\boldsymbol{N}$ & Range & Mean & $\begin{array}{c}\text { Ranks of } \\
\text { Mean }\end{array}$ & $\begin{array}{c}\text { Std. } \\
\text { Deviation }\end{array}$ & $\begin{array}{c}\text { Ranks of Std. } \\
\text { Deviation }\end{array}$ \\
\hline$W_{1}$ & 20 & 0.0221 & 0.0580 & 6 & 0.0051 & 4 \\
\hline$W_{2}$ & 20 & 0.0385 & 0.3033 & 1 & 0.0119 & 2 \\
\hline$W_{3}$ & 20 & 0.0383 & 0.2441 & 2 & 0.0135 & 1 \\
\hline$W_{4}$ & 20 & 0.0116 & 0.0420 & 7 & 0.0032 & 7 \\
\hline$W_{5}$ & 20 & 0.0131 & 0.0744 & 5 & 0.0035 & 6 \\
\hline$W_{6}$ & 20 & 0.0300 & 0.1430 & 3 & 0.0083 & 3 \\
\hline$W_{7}$ & 20 & 0.0165 & 0.1039 & 4 & 0.0047 & 5 \\
\hline$W_{8}$ & 20 & 0.0031 & 0.0313 & 8 & 0.0010 & 8 \\
\hline
\end{tabular}

The descriptive statistics of 20 test problems ${ }^{15}$ in Case 1 and in the proposed NE-BWM are provided in Table 6 . The standard deviation shows that the weights of $W_{3}$ have been more spread out compared to others. No new ranking has been obtained by considering the ranking of mean values.

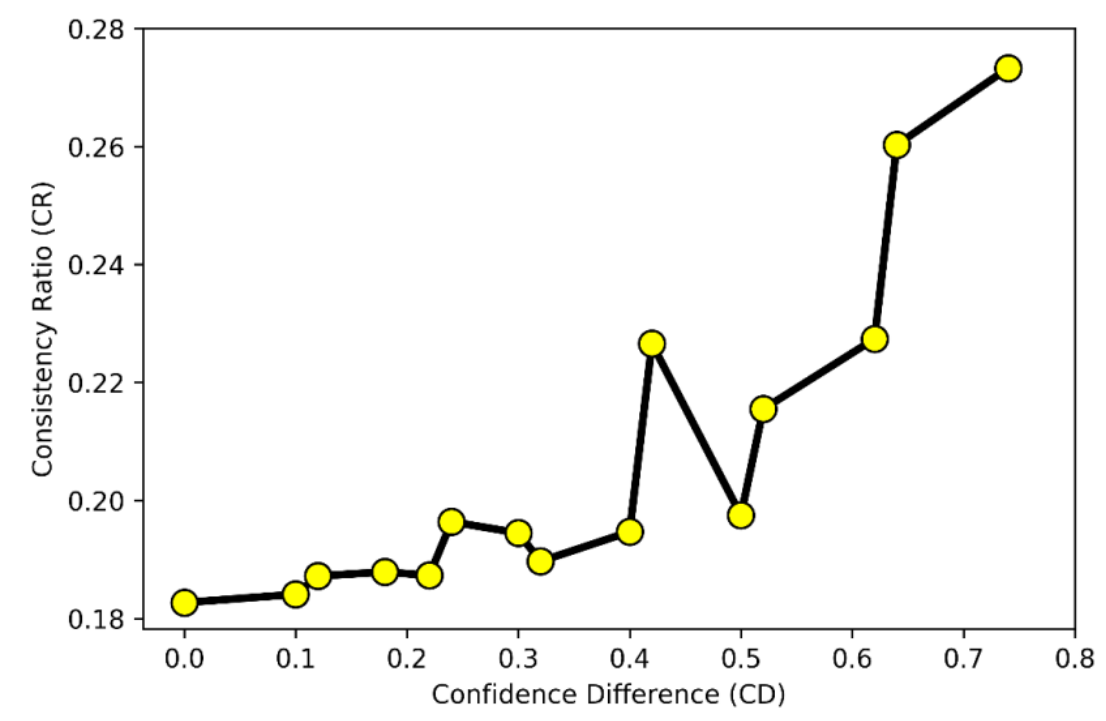

Figure 3. The CR-CD diagram in Case 1

The $C R$ values are moving upward in Case 1 , as $C D$ values increase, showing that the consistency of the comparisons will decrease. Its surge is more vivid while the $C D$ is at the peak

${ }^{15}$ Test problem 1 has not been considered because it regards the weights in the original BWM 
(Figure 3). The highest $C D$ value (i.e., 0.74$)$ appeared in test problem $7\left(\rho^{+}=0.26\right.$ and $\rho^{-}=1.00$

), but, in test problem 7, the ranking remained unchanged compared to the original BWM (Table

5). This point shows that merely increasing $C D$ does not necessarily lead to a change in the ranking, although it reduces the consistency of the DM's comparisons.

\subsection{Case 2: A supply chain social sustainability problem}

Ahmadi et al. (2017) applied the BWM to analyze eight identified social sustainability criteria in a developing economy context. Here, the criteria are assessed by the NE-BWM based on the provided evaluation data (Tables 7 and 8). The social sustainability criteria are work safety and labor health $\left(S S C_{1}\right)$, training education and community development $\left(S S C_{2}\right)$, contractual stakeholders' influence ( $\left.S S C_{3}\right)$, occupational health and safety management system $\left(S S C_{4}\right)$, interests and rights of employees ( $\left.S S C_{5}\right)$, rights of the community $\left(S S C_{6}\right)$, information disclosure $\left(S S C_{7}\right)$, and employment practices $\left(S S C_{8}\right)$. The best social sustainability criterion is work safety and labor health $\left(S S C_{1}\right)$, and the worst social sustainability criterion is the rights of the community $\left(S S C_{6}\right)$ and $a_{B W}=9$. Table 9 shows the $C R$ for the original BWM as $C R=\frac{1.7251}{5.23}=0.3298$, based on the $C I$ table in Rezaei (2015). The threshold in this evaluation is 0.4587 based on the cardinal and output-based consistency measurement (see Liang et al., 2019), indicating the consistency of the pairwise evaluations.

Table 7. Best-to-others vector (Case 2)

\begin{tabular}{|l|c|c|c|c|c|c|c|c|}
\hline Criteria & $S S C_{1}$ & $S S C_{2}$ & $S S C_{3}$ & $S S C_{4}$ & $S S C_{5}$ & $S S C_{6}$ & $S S C_{7}$ & $S S C_{8}$ \\
\hline The Best Criterion $\left(S S C_{1}\right)$ & 1 & 3 & 5 & 4 & 5 & 9 & 5 & 7 \\
\hline
\end{tabular}

Table 8. Others-to-worst vector (Case 2)

\begin{tabular}{|c|c|}
\hline Criteria & $\begin{array}{c}\text { The Worst } \\
\text { Criterion }\left(S S C_{6}\right)\end{array}$ \\
\hline$S S C_{1}$ & 9 \\
\hline
\end{tabular}




\begin{tabular}{|l|l|}
\hline$S S C_{2}$ & 2 \\
\hline$S S C_{3}$ & 5 \\
\hline$S S C_{4}$ & 3 \\
\hline$S S C_{5}$ & 4 \\
\hline$S S C_{6}$ & 1 \\
\hline$S S C_{7}$ & 5 \\
\hline$S S C_{8}$ & 3 \\
\hline
\end{tabular}

Table 9. Analysis of 21 test problems in Case 2

\begin{tabular}{|c|c|c|c|c|c|c|c|c|c|c|c|}
\hline \multicolumn{12}{|c|}{ Original BWM } \\
\hline \multicolumn{2}{|l|}{$N^{\circ}$} & $W_{1}^{*}$ & $W_{2}^{*}$ & $W_{3}^{*}$ & $W_{4}^{*}$ & $W_{5}^{*}$ & $W_{6}^{*}$ & $W_{7}^{*}$ & $W_{8}^{*}$ & $\varepsilon^{*}$ & $C R$ \\
\hline & & 0.3794 & 0.1206 & 0.1158 & 0.0981 & 0.0856 & 0.0354 & 0.1158 & 0.0492 & 1.7251 & 0.3298 \\
\hline 1 & ranking $(0)$ & 1 & 2 & 3 & 4 & 5 & 7 & 3 & 6 & - & - \\
\hline \multicolumn{12}{|c|}{ NE-BWM } \\
\hline & & $W_{1}^{*}$ & $W_{2}^{*}$ & $W_{3}^{*}$ & $W_{4}^{*}$ & $W_{5}^{*}$ & $W_{6}^{*}$ & $W_{7}^{*}$ & $W_{8}^{*}$ & $\varepsilon^{*}$ & $C R$ \\
\hline \multirow{3}{*}{2} & $\rho^{+}=0.26$ & \multirow{2}{*}{0.3431} & \multirow{2}{*}{0.1192} & \multirow{2}{*}{0.1048} & \multirow{2}{*}{0.1265} & \multirow{2}{*}{0.1048} & \multirow{2}{*}{0.0320} & \multirow{2}{*}{0.1048} & \multirow{2}{*}{0.0650} & \multirow{2}{*}{0.4485} & \multirow{2}{*}{0.3664} \\
\hline & $\rho^{-}=0.26$ & & & & & & & & & & \\
\hline & ranking (1) & 1 & 3 & 4 & 2 & 4 & 6 & 4 & 5 & - & - \\
\hline \multirow{3}{*}{3} & $\rho^{+}=0.26$ & \multirow[b]{2}{*}{0.3360} & \multirow{2}{*}{0.1075} & \multirow[b]{2}{*}{0.1152} & \multirow[b]{2}{*}{0.1426} & \multirow[b]{2}{*}{0.0830} & \multirow{2}{*}{0.0322} & \multirow{2}{*}{0.1152} & \multirow[b]{2}{*}{0.0683} & \multirow[b]{2}{*}{0.5417} & \multirow{2}{*}{0.3783} \\
\hline & $\rho^{-}=0.38$ & & & & & & & & & & \\
\hline & ranking (2) & 1 & 4 & 3 & 2 & 5 & 7 & 3 & 6 & - & - \\
\hline \multirow{3}{*}{4} & $\rho^{+}=0.26$ & \multirow{2}{*}{0.3410} & \multirow{2}{*}{0.0650} & & & & & & & & \\
\hline & $\rho^{-}=0.50$ & & & 0.1269 & 0.1405 & 0.0935 & 0.0334 & 0.1269 & 0.0728 & 0.6014 & 0.3890 \\
\hline & ranking (3) & 1 & 6 & 3 & 2 & 4 & 7 & 3 & 5 & - & - \\
\hline & $\rho^{+}=0.26$ & & & 01389 & & & & & & & 04007 \\
\hline 5 & $\rho^{-}=0.68$ & 0.3433 & 0.0950 & 0.1389 & 0.0704 & 0.1091 & 0.0344 & 0.1389 & 0.0700 & 0.6575 & 0.4007 \\
\hline & ranking (4) & 1 & 4 & 2 & 5 & 3 & 7 & 2 & 6 & - & - \\
\hline & $\rho^{+}=0.26$ & & & & & & & & & & \\
\hline 6 & $\rho^{-}=0.90$ & 0.3411 & 0.0602 & 0.1474 & 0.0776 & 0.1125 & 0.0349 & 0.1474 & 0.0791 & 0.6983 & 0.4103 \\
\hline & ranking (5) & 1 & 6 & 2 & 5 & 3 & 7 & 2 & 4 & - & - \\
\hline & $\rho^{+}=0.26$ & & & & & & & & & & \\
\hline 7 & $\rho^{-}=1.00$ & 0.3196 & 0.0601 & 0.1410 & 0.1222 & 0.1081 & 0.0329 & 0.1410 & 0.0752 & 0.7147 & 0.4153 \\
\hline & ranking (6) & 1 & 6 & 2 & 3 & 4 & 7 & 2 & 5 & - & - \\
\hline & $\rho^{+}=0.38$ & & & & & & & & & & \\
\hline 8 & $\rho^{-}=0.38$ & 0.3509 & 0.0743 & 0.1071 & 0.1542 & 0.1071 & 0.0327 & 0.1071 & 0.0665 & 0.6555 & 0.3664 \\
\hline & ranking (7) & 1 & 4 & 3 & 2 & 3 & 6 & 3 & 5 & - & - \\
\hline & $\rho^{+}=0.38$ & & & & & & & & & & \\
\hline 9 & $\rho^{-}=0.50$ & 0.3552 & 0.0712 & 0.1179 & 0.1491 & 0.0841 & 0.0338 & 0.1179 & 0.0708 & 0.7553 & $0.3 / 45$ \\
\hline & ranking (8) & 1 & 5 & 3 & 2 & 4 & 7 & 3 & 6 & - & - \\
\hline 10 & $\rho^{+}=0.38$ & 0.3662 & 0.0973 & 0.1335 & 0.0621 & 0.1097 & 0.0357 & 0.1335 & 0.0621 & 0.8573 & 0.3862 \\
\hline
\end{tabular}




\begin{tabular}{|c|c|c|c|c|c|c|c|c|c|c|c|}
\hline & $\rho^{-}=0.68$ & & & & & & & & & & \\
\hline & ranking (9) & 1 & 4 & 2 & 5 & 3 & 6 & 2 & 5 & - & - \\
\hline & $\rho^{+}=0.38$ & \multirow{2}{*}{0.3552} & \multirow{2}{*}{0.0650} & \multirow{2}{*}{0.1401} & \multirow{2}{*}{0.0715} & \multirow{2}{*}{0.1145} & \multirow{2}{*}{0.0354} & \multirow{2}{*}{0.1401} & \multirow{2}{*}{0.0783} & \multirow{2}{*}{0.9364} & \multirow{2}{*}{0.3971} \\
\hline 11 & $\rho^{-}=0.90$ & & & & & & & & & & \\
\hline & ranking (5) & 1 & 6 & 2 & 5 & 3 & 7 & 2 & 4 & - & - \\
\hline \multirow{3}{*}{12} & $\rho^{+}=0.38$ & \multirow{2}{*}{0.3556} & \multirow{2}{*}{0.0665} & \multirow{2}{*}{0.1441} & \multirow{2}{*}{0.0727} & \multirow{2}{*}{0.1084} & \multirow{2}{*}{0.0357} & \multirow{2}{*}{0.1441} & \multirow{2}{*}{0.0727} & \multirow{2}{*}{0.9624} & \multirow{2}{*}{0.4010} \\
\hline & $\rho^{-}=1.00$ & & & & & & & & & & \\
\hline & $\begin{array}{l}\text { ranking } \\
(10)\end{array}$ & 1 & 5 & 2 & 4 & 3 & 6 & 2 & 4 & - & - \\
\hline \multirow{3}{*}{13} & $\rho^{+}=0.50$ & \multirow{2}{*}{0.3552} & \multirow{2}{*}{0.1234} & \multirow{2}{*}{0.1085} & \multirow{2}{*}{0.0963} & 01005 & & 01005 & 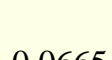 & 00605 & 0266 \\
\hline & $\rho^{-}=0.50$ & & & & & 0.1085 & 0.0331 & 0.1085 & 0.0665 & 0.8625 & 0.3664 \\
\hline & $\begin{array}{l}\text { ranking } \\
\text { (11) }\end{array}$ & 1 & 2 & 3 & 4 & 3 & 6 & 3 & 5 & - & - \\
\hline & $\rho^{+}=0.50$ & & & & & & & & & & \\
\hline 14 & $\rho^{-}=0.68$ & $0.35 / 1$ & 0.1093 & 0.1151 & 0.1145 & 0.1151 & 0.0322 & 0.1151 & $0.00 / 1$ & 1.0091 & ו וכוכ \\
\hline & ranking (7) & 1 & 4 & 3 & 2 & 3 & 6 & 3 & 5 & - & - \\
\hline & $\rho^{+}=0.50$ & & & & & & & & & & \\
\hline 15 & $\rho^{-}=0.90$ & 0.3029 & 0.1152 & 0.1525 & 0.0011 & 0.0971 & 0.0354 & 0.1525 & 0.0021 & 1.1504 & 0.5805 \\
\hline & $\begin{array}{l}\text { ranking } \\
\text { (12) }\end{array}$ & 1 & 3 & 2 & 6 & 4 & 7 & 2 & 5 & - & - \\
\hline & $\rho^{+}=0.50$ & 0057 & 0110 & 018 & 0 & ת & 0025 & 40 & & & \\
\hline 16 & $\rho^{-}=1.00$ & $0.35 / 1$ & 0.1113 & 0.1344 & 0.0642 & 0.0993 & 0.0351 & 0.1344 & 0.0642 & 1.1716 & 0.3905 \\
\hline & $\begin{array}{c}\text { ranking } \\
\text { (13) }\end{array}$ & 1 & 3 & 2 & 5 & 4 & 6 & 2 & 5 & - & - \\
\hline & $\rho^{+}=0.68$ & & & & & & & & & & \\
\hline 17 & $\rho^{-}=0.68$ & $0.5 / 02$ & $0.150 /$ & 0.1147 & 0.0001 & 0.1149 & 0.0351 & 0.1149 & $0.044 /$ & $1.1 / 31$ & 0.3064 \\
\hline & $\begin{array}{c}\text { ranking } \\
(11)\end{array}$ & 1 & 2 & 3 & 4 & 3 & 6 & 3 & 5 & - & - \\
\hline & $\rho^{+}=0.68$ & ( & 0.101 & 019 & 0 & $0=0$ & ค & P 14 & م & 1055 & 7074 \\
\hline 18 & $\rho^{-}=0.90$ & 0.3358 & 0.1121 & 0.1117 & 0.1440 & 0.1050 & 0.0320 & 0.1111 & $0.04 / 8$ & 1.3554 & $0.3 / 4 /$ \\
\hline & $\begin{array}{l}\text { ranking } \\
(14)\end{array}$ & 1 & 3 & 4 & 2 & 5 & 7 & 4 & 6 & - & - \\
\hline & $\rho^{+}=0.68$ & סרד 00 & & & & & & & & & (0) \\
\hline 19 & $\rho^{-}=1.00$ & 0.3738 & 0.1227 & 0.1284 & 0.0614 & 0.0925 & 0.0359 & 0.1284 & 0.0568 & 1.4204 & $0.3 / 86$ \\
\hline & $\begin{array}{c}\text { ranking } \\
\text { (15) }\end{array}$ & 1 & 3 & 2 & 5 & 4 & 7 & 2 & 6 & - & - \\
\hline & $\rho^{+}=0.90$ & & & & & & & 7 & & & \\
\hline 20 & $\rho^{-}=0.90$ & 0.3428 & 0.1191 & 0.1047 & $0.150 /$ & 0.1010 & 0.0320 & $0.104 /$ & 0.0445 & 1.5526 & 0.3664 \\
\hline & $\begin{array}{c}\text { ranking } \\
(14)\end{array}$ & 1 & 3 & 4 & 2 & 5 & 7 & 4 & 6 & - & - \\
\hline & $\rho^{+}=0.90$ & 0.3731 & 0.1088 & 0.1176 & 0.0717 & 0.1176 & 0.0350 & 0.1176 & 0.0586 & 1.6447 & 0.3692 \\
\hline
\end{tabular}




\begin{tabular}{|c|c|c|c|c|c|c|c|c|c|c|c|}
\hline 21 & $\rho^{-}=1.00$ & & & & & & & & & & \\
\hline & $\begin{array}{c}\text { ranking } \\
(16)\end{array}$ & 1 & 3 & 2 & 4 & 2 & 6 & 2 & 5 & - & - \\
\hline
\end{tabular}

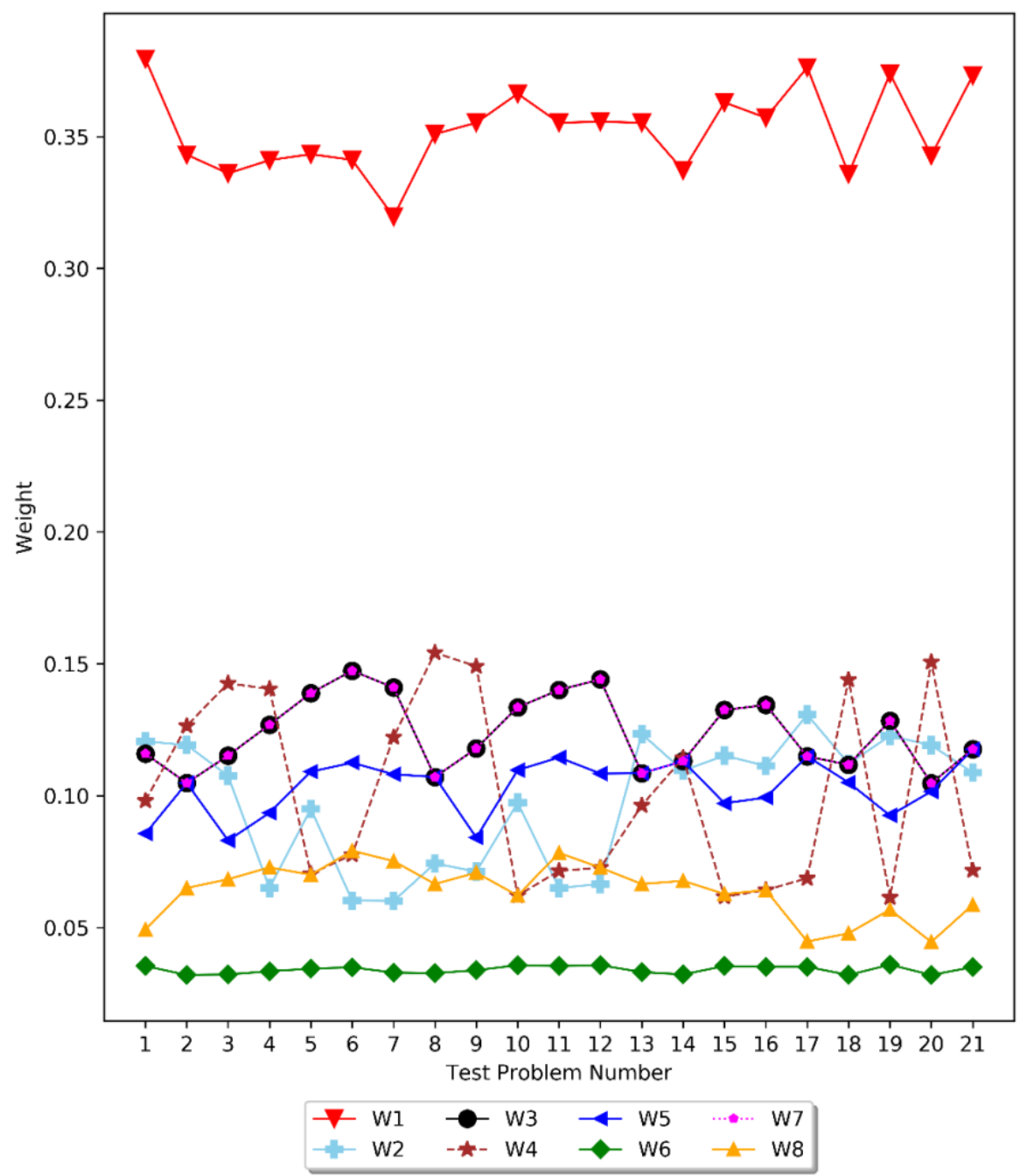

Figure 4. Trend and ranking of weights in 21 test problems in Case 2

Table 9 also presents the results of the analysis for 21 test problems in Case 2. As shown in this table, no ranking identical to the original BWM ranking has been obtained when taking into consideration various $\rho^{+}$and $\rho^{-}$values in 20 test problems of the NE-BWM. Figure 4, depicts the trend and rankings of the weights in each test problem in Case 2. The best criterion's weight $\left(W_{1}\right)$ is considerably higher than other weights, which has made other diagrams closer to each other and has resulted in various rankings under $\rho^{+}$and $\rho^{-}$values (Figure 4). In total, 16 new 
rankings are obtained in addition to the ranking provided by the original BWM (Table 9).

Table 10. The NE-BWM weights analysis in Case 2

\begin{tabular}{|c|c|c|c|c|c|c|}
\hline Weights & $N$ & Range & Mean & $\begin{array}{c}\text { Ranks of } \\
\text { Mean }\end{array}$ & $\begin{array}{c}\text { Std. } \\
\text { Deviation }\end{array}$ & $\begin{array}{c}\text { Ranks of Std. } \\
\text { Deviation }\end{array}$ \\
\hline$W_{1}$ & 20 & 0.0566 & 0.3511 & 1 & 0.0148 & 3 \\
\hline$W_{2}$ & 20 & 0.0706 & 0.0967 & 5 & 0.0246 & 2 \\
\hline$W_{3}$ & 20 & 0.0427 & 0.1241 & 2 & 0.0141 & 4 \\
\hline$W_{4}$ & 20 & 0.0928 & 0.1011 & 4 & 0.0363 & 1 \\
\hline$W_{5}$ & 20 & 0.0346 & 0.1042 & 3 & 0.0099 & 6 \\
\hline$W_{6}$ & 20 & 0.0039 & 0.0339 & 7 & 0.0015 & 7 \\
\hline$W_{7}$ & 20 & 0.0427 & 0.1241 & 2 & 0.0141 & 4 \\
\hline$W_{8}$ & 20 & 0.0346 & 0.0647 & 6 & 0.0101 & 5 \\
\hline
\end{tabular}

The descriptive statistics of 20 test problems in Case 2 in the proposed NE-BWM are provided in Table 10. The standard deviation shows that weights of $W_{4}$ have changed more erratically. The mean values of weights in Case 2 have generated a new unique ranking. This result indicates that the mean weight may be able to represent an aggregated weight ranking by taking into account all of the uncertainties.

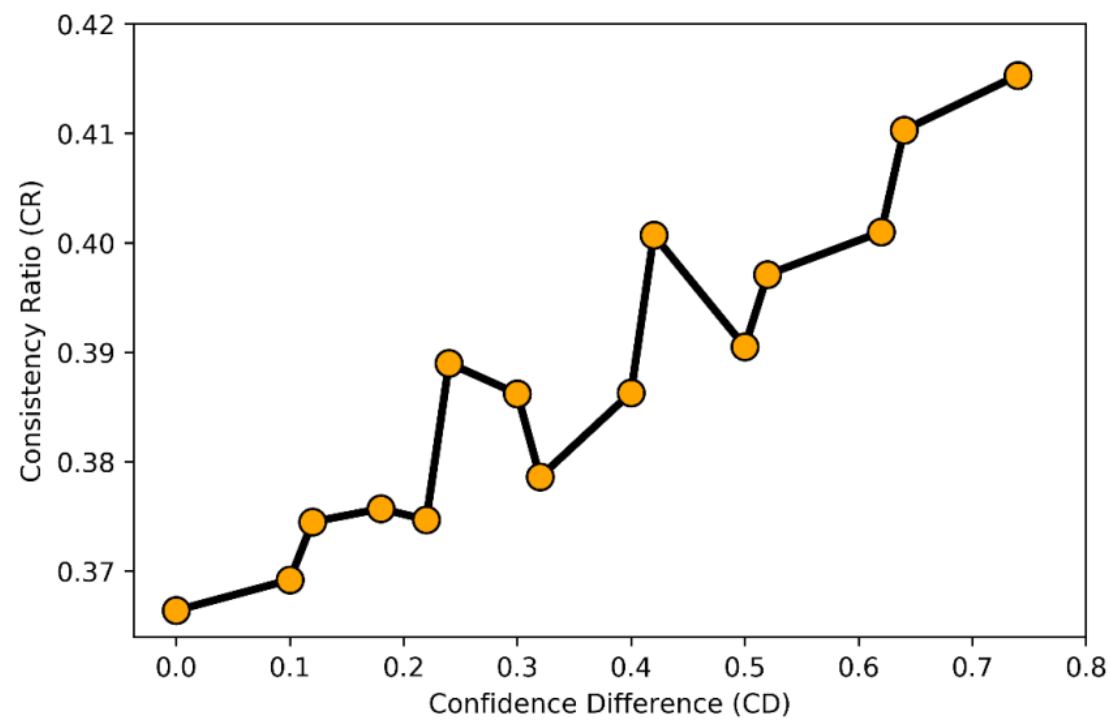

Figure 5. The CR-CD diagram in Case 2

Like Case 1, the $C R-C D$ diagram in Case 2 has an increasing trend, which means the greater the $C D$ value, the higher $C R$, and the lower the consistency (Figure 5). The $C R-C D$ 
diagram in Case 2, has a slightly more erratic trend compared to Case 1.

\section{Discussion}

To capture the DM's uncertainty in selecting the best and worst criteria and subsequently, the resulted comparisons in the original BWM, we proposed two parameters that were defined as $0<\rho^{+} \leq 1$ and $0<\rho^{-} \leq 1$. In other words, in the original BWM, obtaining the criteria weights was irrespective of how certain a DM was about the two separations ( $I$ and $I I$ ). The reason was that the two separations ( $I$ and $I I$ ) were treated with equal importance while in real-world decisionmaking problems, it would not be very realistic, mainly due to DMs' indeterminacy in selecting the best and worst criteria and consequently in the provided comparisons. To be more clear, this lack of confidence could result from two interdependent causes: (1) hesitancy in opting the best and worst criteria and (2) uncertainty or lack of confidence in the provided preferences (separations $I$ and $I I) . \rho^{+}$and $\rho^{-}$are the subjective values reflecting the DMs' opinions. Based on the NST

(Table 2), $\rho^{+}$and $\rho^{-}$represent the DM's degree of confidence in separations $I$ and $I I$. Test problem 1 (i.e., the original BWM) is calculated when the DMs have the highest possible confidence in the two separations (i.e., $\rho^{+}=1$ and $\rho^{-}=1$ ), which is the decision without uncertainty.

The NE-BWM analyses show that in Cases 1 and 2, various weight rankings were obtained under different $\rho^{+}$and $\rho^{-}$values in 21 test problems. In both cases, there are eight criteria with the same $a_{B W}=9$. In addition, regarding the original BWM, we have $C R=0.1644$ (Case 1) and $C R=0.3298$ (Case 2). Under various DMs' confidence levels in separations $I$ and $I I$ (i.e., $\rho^{+}$ and $\rho^{-}$values), sixteen new rankings were obtained in Case 2 and only one new ranking in Case 1 (Tables 5 and 9). Obtaining so many or few new different rankings distinctive to the original 
BWM ranking represents how the resulted ranking can potentially be influenced and altered by the DMs' uncertain opinions compared to the original BWM. It shows that by not considering two uncertainty parameters, the original BWM might not be generating the most suitable and reliable result, which validates the need for an uncertainty extension of the original BWM.

In this study, a new measurement index of the NE-BWM output $(C D)$ has been proposed to better explain the consistency alteration in the provided comparisons. Results in both Cases show that an increase in the $C D$ values would raise the $C R$ values, which indicates lower consistency in the comparisons and the DMs' judgments (Figures 3 and 5). This means that the consistency of evaluations is susceptible to unbalanced confidence of DMs in the two separations $I$ and $I I$ (i.e., a higher $C D$ value) in the two Cases. This shows the integration of uncertainty with the BWM can lead to higher inconsistency, as was already indicated in the literature. Recently, Liang et al. (2019) determined acceptable threshold values of $C R$ in the BWM.

The changes in $C R$ values are more significant in Case 2 (Figure 5). The $C R$ value in the original BWM in Case 2 (i.e., $C R=0.3298$ ) is higher than its corresponding value in Case 1 (i.e., $C R=0.1644$ ). The reason for the significant change in $C R$ of Case 2 is because its $C R$ value in the original BWM shows higher inconsistency than in Case 1. Thus, the effect of a change in the DMs' confidence in separations $I$ and $I I$ ( $C D$ value alterations) would be more influential on $C R$ values in Case 2 (noting that in the original BWM there is full confidence in the separations $I$ and $I I)$.

It is also concluded that there is no direct relation between $C D$ and a change in ranking in the test problems of Cases 1 and 2. For instance, having the highest $C D$ value (i.e., 0.74) in Case 1 did not alter the rankings. However, in Case 2, having the slightest $C D$ value alterations produced new rankings. This finding shows $C D$ alone cannot contribute to a change in ranking, 
and $C R$ values should be taken into consideration. Suppose, a DM is completely confident about their comparisons and has chosen the best and worst criteria (i.e., $\rho^{+}=1.00, \rho^{-}=1.00$, and $C D=0)$ but the comparisons are suffering from high $C R$ value. In this instance, it would cause the outcome rankings to become more sensitive to a little skepticism of a DM on their choice about either Separation I or Separation II (an uncertain DM, or when $C D>0$ ).

\section{Conclusions and Future Research Directions}

This study focused on the methodological development of the original BWM. It revealed a need to improve the original BWM and proposed an uncertain extension of the method based on the NST. The degree of the DMs' confidence in the best-to-others preferences (Separation $I$ ) and others-to-worst preferences (Separation II ) have been overlooked in the original BWM. The NEBWM was proposed to overcome it and improve the efficiency of the original BWM in the realworld applications in uncertain environments. The validity of the proposed NE-BWM was analyzed in two real-world cases in supply chain management. In each case, 20 test problems were analyzed and compared with one test problem of the original BWM (i.e., in total 21 test problems). The $C R$ calculation in the NE-BWM was also elaborated in detail. Furthermore, a new measurement index named $C D$ was proposed, which takes into consideration the extent of the discrepancy between the DMs' evaluations on the separations I and II. The overall outcomes from the analysis of the two cases can be summarized as follows:

- The new NE-BWM model can change the final ranking of the criteria weights. This change in ranking represents how the resulted ranking can be potentially influenced and altered by the DMs' uncertain opinions compared to the fully confident deterministic approach of the DMs in the original BWM. This result shows that under uncertain real-world applications, the original BWM might not be able to generate the most suitable criteria weights and, 
consequently, the most reliable ranking because it considers DMs are fully confident and there is no hesitancy on their part.

- With growing inconsistency, the DMs' degree of confidence in the separations $I$ and $I I$ can play a more critical role in obtaining new rankings. In other words, when the original BWM comparisons are consistent (smaller $C R$ values), then the proposed NE-BWM cannot significantly affect the criteria weights and rankings under various $\rho^{+}$and $\rho^{-}$values in different test problems. It means that the final ranking and weights are more sensitive to the inconsistency of comparisons under various $\rho^{+}$and $\rho^{-}$values in different test problems.

- An increase in $C D$ values, meaning unbalanced confidence of DMs in the two separations $I$ and $I I$ would raise the $C R$ values indicating less consistency in comparisons.

- The changes in $C R$ values can be more considerable due to higher inconsistency, which makes the changes in $C R$ more susceptible to $C D$ value alterations.

- The mean values of weights can be represented as an aggregated weight and produce a unique ranking (i.e., in Case 2, Table 10). In some circumstances, applying this aggregated weight might be helpful. This would include situations where acquiring the DMs' confidence is impossible because the data is already gathered, and there is no more access to DMs or for reanalyzing the other original BWM studies by the NE-BWM.

The NE-BWM can assist decision-makers to achieve more reliable rankings in real-world decision-making problems. In future research directions, firstly, a simulation approach can be a reasonable solution to overcome the issue of a limited number of application cases to provide more generalizable findings. That is, by a larger sample or numerical simulations, the generalizability of the obtained relationship between $C D$ and $C R$ can be confirmed in our case studies. Secondly, given that uncertainty leads to higher inconsistency in our case studies; thus, there would be a 
necessity for processes that mitigate inconsistency to be further investigated. Thirdly, the proposed model can also be compared to the other extensions of the original BWM integrated with uncertainty theories like the fuzzy set theory. For instance, it would be interesting to use intervalvalued neutrosophic or the Pythagorean fuzzy set with the enhanced BWM to measure the confidence levels of experts and compare the result with the NE-BWM.

\section{Acknowledgment}

The authors would like to thank the anonymous reviewers and the editor for their insightful comments and suggestions. Amin Vafadarnikjoo would like to acknowledge the Post-Graduate Research Scholarship from the University of East Anglia, Social Science Faculty (SSF) and Research Training Support Grant (RTSG) which supported him in this research at Norwich Business School. Dr. Madjid Tavana is grateful for the partial support he received from the Czech Science Foundation (GACR19-13946S) for this research. 


\section{References}

Abdel-Baset, M., Chang, V., Gamal, A., \& Smarandache, F. (2019). An integrated neutrosophic ANP and VIKOR method for achieving sustainable supplier selection: A case study in importing field. Computers in Industry, 106, 94-110.

Aboutorab, H., Saberi, M., Asadabadi, M. R., Hussain, O., \& Chang, E. (2018). ZBWM: The Znumber extension of Best Worst Method and its application for supplier development. Expert Systems with Applications, 107, 115-125.

Ahmadi, H. B., Kusi-Sarpong, S., \& Rezaei, J. (2017). Assessing the social sustainability of supply chains using Best Worst Method. Resources, Conservation and Recycling, 126, 99-106.

Alimohammadlou, M., \& Bonyani, A. (2018). A comparative analysis of dynamic and crosssectional approaches for financial performance analysis. American Journal of Finance and Accounting, 5(3), 253-275.

Alsalem, M. A., Zaidan, A. A., Zaidan, B. B., Hashim, M., Albahri, O. S., Albahri, A. S., ... \& Mohammed, K. I. (2018). Systematic review of an automated multiclass detection and classification system for acute Leukaemia in terms of evaluation and benchmarking, open challenges, issues and methodological aspects. Journal of Medical Systems, 42(11), 204.

Amoozad Mahdiraji, H., Arzaghi, S., Stauskis, G., \& Zavadskas, E. (2018). A hybrid fuzzy BWMCOPRAS method for analyzing key factors of sustainable architecture. Sustainability, 10(5), 1626.

Asadabadi, M. R., Chang, E., Zwikael, O., Saberi, M., \& Sharpe, K. (2020). Hidden Fuzzy Information: Requirement specification and measurement of project provider performance using the best worst method. Fuzzy Sets and Systems, 383, 127-145.

Ashraf, S., Abdullah, S., \& Smarandache, F. (2019). Logarithmic Hybrid Aggregation Operators Based on Single Valued Neutrosophic Sets and Their Applications in Decision Support Systems. Symmetry, 11(3), 364.

Atanassov, K.T. (1986). Intuitionistic fuzzy sets. Fuzzy Sets and Systems, 20(1), 87-96.

Bai, C., Kusi-Sarpong, S., Badri Ahmadi, H., \& Sarkis, J. (2019). Social sustainable supplier evaluation and selection: a group decision-support approach. International Journal of Production Research, 57(22), 7046-7067. https://doi.org/10.1080/00207543.2019.1574042

Baudry, G., Macharis, C., \& Vallee, T. (2018). Range-based Multi-Actor Multi-Criteria Analysis: A combined method of Multi-Actor Multi-Criteria Analysis and Monte Carlo simulation to support participatory decision making under uncertainty. European Journal of Operational Research, 264(1), 257-269.

Beemsterboer, D. J. C., Hendrix, E. M. T., \& Claassen, G. D. H. (2018). On solving the Best- 
Worst Method in multi-criteria decision-making. IFAC-PapersOnLine, 51(11), 1660-1665.

Biswas, P., Pramanik, S., \& Giri, B. C. (2016). TOPSIS method for multi-attribute group decisionmaking under single-valued neutrosophic environment. Neural Computing and Applications, 27(3), 727-737.

Bolturk, E., \& Kahraman, C. (2018). A novel interval-valued neutrosophic AHP with cosine similarity measure. Soft Computing, 22(15), 4941-4958.

Booker, J. M., \& Ross, T. J. (2011). An evolution of uncertainty assessment and quantification. Scientia Iranica, 18(3), 669-676.

Cheraghalipour, A., \& Farsad, S. (2018). A bi-objective sustainable supplier selection and order allocation considering quantity discounts under disruption risks: A case study in plastic industry. Computers \& Industrial Engineering, 118, 237-250.

Cheraghalipour, A., Paydar, M. M., \& Hajiaghaei-Keshteli, M. (2018). Applying a hybrid BWMVIKOR approach to supplier selection: a case study in the Iranian agricultural implements industry. International Journal of Applied Decision Sciences, 11(3), 274-301.

Deli, I., \& Subas, Y. (2014). Single valued neutrosophic numbers and their applications to multicriteria decision making problem. Neutrosophic Sets and Systems, 2(1), 1-13.

Dempster, A. P. (1968). A generalization of Bayesian inference. Journal of the Royal Statistical Society: Series B (Methodological), 30(2), 205-232.

Dong, Y., Liu, W., Chiclana, F., Kou, G., \& Herrera-Viedma, E. (2019). Are incomplete and selfconfident preference relations better in multicriteria decision making? A simulation-based investigation. Information Sciences, 492, 40-57.

Doumpos, M., \& Zopounidis, C. (2002). Multiattributes decision aid classification methods. Boston: Kluwer Academic.

Dubois, D., \& Prade, H. (2012). Possibility theory (pp. 2240-2252). Springer New York.

Ferreira, F. A., \& Meidute-Kavaliauskienė, I. (2019). Toward a sustainable supply chain for social credit: learning by experience using single-valued neutrosophic sets and fuzzy cognitive maps. Annals of Operations Research. https://doi.org/10.1007/s10479-019-03194-2

Garg, C. P., \& Sharma, A. (2020). Sustainable outsourcing partner selection and evaluation using an integrated BWM-VIKOR framework. Environment, Development and Sustainability, 22, 1529-1557. https://doi.org/10.1007/s10668-018-0261-5

Govindan, K., \& Jepsen, M. B. (2016). ELECTRE: A comprehensive literature review on methodologies and applications. European Journal of Operational Research, 250(1), 1-29.

Govindan, K., Khodaverdi, R., \& Vafadarnikjoo, A. (2015). Intuitionistic fuzzy based DEMATEL method for developing green practices and performances in a green supply chain. Expert 
Systems with Applications, 42(20), 7207-7220.

Guo, S., \& Zhao, H. (2017). Fuzzy best-worst multi-criteria decision-making method and its applications. Knowledge-Based Systems, 121, 23-31.

Gupta, H. (2018a). Evaluating service quality of airline industry using hybrid best worst method and VIKOR. Journal of Air Transport Management, 68, 35-47.

Gupta, H. (2018b). Assessing organizations performance on the basis of GHRM practices using BWM and Fuzzy TOPSIS. Journal of Environmental Management, 226, 201-216.

Gupta, H., \& Barua, M. K. (2018). A novel hybrid multi-criteria method for supplier selection among SMEs on the basis of innovation ability. International Journal of Logistics Research and Applications, 21(3), 201-223.

Hafezalkotob, A., \& Hafezalkotob, A. (2017). A novel approach for combination of individual and group decisions based on fuzzy best-worst method. Applied Soft Computing, 59, 316-325.

Huang, I. B., Keisler, J., \& Linkov, I. (2011). Multi-criteria decision analysis in environmental sciences: ten years of applications and trends. Science of the Total Environment, 409(19), 3578-3594.

Ishizaka, A. (2012). Clusters and pivots for evaluating a large number of alternatives in AHP. Pesquisa Operacional, 32(1), 87-102.

Joslyn, C., \& Booker, J. M. (2004). Generalized information theory for engineering modeling and simulation. In Engineering Design Reliability Handbook (pp. 157-196). CRC Press.

Ji, P., Wang, J. Q., \& Zhang, H. Y. (2018). Frank prioritized Bonferroni mean operator with singlevalued neutrosophic sets and its application in selecting third-party logistics providers. Neural Computing and Applications, 30(3), 799-823.

Kämpke, T. (1988). About assessing and evaluating uncertain inferences within the theory of evidence. Decision Support Systems, 4(4), 433-439.

Kocak, H., Caglar, A., \& Oztas, G. Z. (2018). Euclidean Best-Worst Method and Its Application. International Journal of Information Technology \& Decision Making, 17(5), 1587-1605.

Kumar, D. N. (2010). Multicriterion analysis in engineering and management. PHI Learning Pvt. Ltd.

Kuo, T. (2017). A modified TOPSIS with a different ranking index. European Journal of Operational Research, 260(1), 152-160.

Levary, R. R., \& Wan, K. (1998). A simulation approach for handling uncertainty in the analytic hierarchy process. European Journal of Operational Research, 106(1), 116-122.

Liang, F., Brunelli, M., \& Rezaei, J. (2019). Consistency issues in the best worst method: Measurements and thresholds. Omega. In Press, Corrected Proof. 


\section{https://doi.org/10.1016/j.omega.2019.102175}

Li, J., Wang, J. Q., \& Hu, J. H. (2019). Multi-criteria decision-making method based on dominance degree and BWM with probabilistic hesitant fuzzy information. International Journal of Machine Learning and Cybernetics, 10, 1671-1685.

Liu, A., Xiao, Y., Ji, X., Wang, K., Tsai, S. B., Lu, H., ... \& Wang, J. (2018a). A novel two-stage integrated model for supplier selection of green fresh product. Sustainability, 10(7), 2371.

Liu, S., Hu, Y., \& Zhang, Y. (2018b). Supply chain partner selection under cloud computing environment: an improved approach based on BWM and VIKOR. Mathematical Problems in Engineering. https://doi.org/10.1155/2018/7012827

Lo, H. W., Liou, J. J., Wang, H. S., \& Tsai, Y. S. (2018). An integrated model for solving problems in green supplier selection and order allocation. Journal of Cleaner Production, 190, 339352.

Maghsoodi, A. I., Mosavat, M., Hafezalkotob, A., \& Hafezalkotob, A. (2019). Hybrid hierarchical fuzzy group decision-making based on information axioms and BWM: Prototype design selection. Computers \& Industrial Engineering, 127, 788-804.

Marttunen, M., Lienert, J., \& Belton, V. (2017). Structuring problems for Multi-Criteria Decision Analysis in practice: A literature review of method combinations. European Journal of Operational Research, 263(1), 1-17.

Mi, X., Tang, M., Liao, H., Shen, W., \& Lev, B. (2019). The state-of-the-art survey on integrations and applications of the best worst method in decision making: Why, what, what for and what's next?. Omega, 87, 205-225.

Mou, Q., Xu, Z., \& Liao, H. (2017). A graph based group decision making approach with intuitionistic fuzzy preference relations. Computers \& Industrial Engineering, 110, 138150.

Mou, Q., Xu, Z., \& Liao, H. (2016). An intuitionistic fuzzy multiplicative best-worst method for multi-criteria group decision making. Information Sciences, 374, 224-239.

Mulliner, E., Malys, N., \& Maliene, V. (2016). Comparative analysis of MCDM methods for the assessment of sustainable housing affordability. Omega, 59, 146-156.

Mulliner, E., Smallbone, K., \& Maliene, V. (2013). An assessment of sustainable housing affordability using a multiple criteria decision making method. Omega, 41(2), 270-279.

Nancy, \& Garg, H. (2019). A novel divergence measure and its based TOPSIS method for multi criteria decision-making under single-valued neutrosophic environment. Journal of Intelligent \& Fuzzy Systems, 36(1), 101-115.

Omrani, H., Amini, M., \& Alizadeh, A. (2020). An integrated group best-worst method-Data 
envelopment analysis approach for evaluating road safety: A case of Iran. Measurement, 152, 107330.

Omrani, H., Alizadeh, A., \& Emrouznejad, A. (2018). Finding the optimal combination of power plants alternatives: A multi response Taguchi-neural network using TOPSIS and fuzzy best-worst method. Journal of Cleaner Production, 203, 210-223.

Pamucar, D., Chatterjee, K., \& Zavadskas, E. K. (2019). Assessment of third-party logistics provider using multi-criteria decision-making approach based on interval rough numbers. Computers \& Industrial Engineering, 127, 383-407.

Rezaei, J. (2016). Best-worst multi-criteria decision-making method: Some properties and a linear model. Omega, 64, 126-130.

Rezaei, J. (2015). Best-worst multi-criteria decision-making method. Omega, 53, 49-57.

Rezaei, J., Wang, J., \& Tavasszy, L. (2015). Linking supplier development to supplier segmentation using Best Worst Method. Expert Systems with Applications, 42(23), 91529164.

Saaty, T. L. (2005). Analytic hierarchy process. Encyclopedia of Biostatistics. John Wiley \& Sons, Ltd., New York. https://doi.org/10.1002/0470011815.b2a4a002

Saaty, T. L. (1977). A scaling method for priorities in hierarchical structures. Journal of Mathematical Psychology, 15(3), 234-281.

Shafer, G. (1976). A mathematical theory of evidence (Vol. 42). Princeton university press.

Smarandache. F. (2005). Neutrosophic set-a generalization of the intuitionistic fuzzy set. International Journal of Pure and Applied Mathematics, 24(3), 287-297.

Smarandache, F. (2002). Neutrosophy, A new branch of philosophy. Multiple Valued Logic: An International Journal, 8(3), 297-384.

Smarandache, F. (1999). A unifying field in Logics: Neutrosophic Logic. In Philosophy (pp. 1141). American Research Press.

Tavana, M., \& Hatami-Marbini, A. (2011). A group AHP-TOPSIS framework for human spaceflight mission planning at NASA. Expert Systems with Applications, 38(11), 1358813603.

Temur, G. T. (2016). A novel multi attribute decision making approach for location decision under high uncertainty. Applied Soft Computing, 40, 674-682.

Vafadarnikjoo, A., Mishra, N., Govindan, K., \& Chalvatzis, K. (2018). Assessment of consumers' motivations to purchase a remanufactured product by applying Fuzzy Delphi method and single valued neutrosophic sets. Journal of Cleaner Production, 196, 230-244.

Vishnupriyan, J., \& Manoharan, P. S. (2018). Multi-criteria decision analysis for renewable energy 
integration: A southern India focus. Renewable Energy, 121, 474-488.

Walley, P. (1991). Statistical reasoning with imprecise probabilities. Chapman and Hall, London and New York.

Wang, H., Smarandache, F., Zhang, Y.Q., \& Sunderraman, R. (2010). Single valued neutrosophic sets. Multispace and Multistructure, 4, 410-413.

Wang, J.Q., \& Zhong, Z. (2009). Aggregation operators on intuitionistic trapezoidal fuzzy number and its applica- tion to multi-criteria decision making problems. Systems Engineering and Electronics, 20(2), 321-326.

Yadav, G., Mangla, S. K., Luthra, S., \& Jakhar, S. (2018). Hybrid BWM-ELECTRE-based decision framework for effective offshore outsourcing adoption: a case study. International Journal of Production Research, 56(18), 6259-6278.

Yamaguchi, D., Li, G. D., Chen, L. C., \& Nagai, M. (2007, November). Reviewing crisp, fuzzy, grey and rough mathematical models. In 2007 IEEE International Conference on Grey Systems and Intelligent Services (pp. 547-552). IEEE.

Ye, J. (2017). Some weighted aggregation operators of trapezoidal neutrosophic numbers and their multiple attribute decision making method. Informatica, 28(2), 387-402.

Ye, J. (2014). Single valued neutrosophic cross-entropy for multicriteria decision making problems. Applied Mathematical Modelling, 38(3), 1170-1175.

Zadeh, L. A. (1965). Fuzzy sets. Information and Control, 8(3), 338-353.

Zhao, H., Guo, S., \& Zhao, H. (2018). Comprehensive performance assessment on various battery energy storage systems. Energies, 11(10), 2841.

Zimmermann, H. J. (2000). An application-oriented view of modeling uncertainty. European Journal of Operational Research, 122(2), 190-198. 


\section{Appendix A: Preliminaries on the neutrosophic set theory (NST)}

Smarandache (1999) introduced the NST as a rigorous general framework for generalizing the concept of IFS. Smarandache (2005) elaborated on the differences between the NS and the IFS theories. The neutrosophic set can independently quantify truth-membership (or membership), indeterminacy-membership, and falsity-membership (or non-membership) functions (Vafadarnikjoo et al., 2018; Ye, 2014). Govindan et al. (2015) have reviewed some fundamental definitions of the IFS theory, and intuitionistic fuzzy numbers. Several researchers have recently integrated the NST with decision-making techniques such as ANP and VIKOR (Abdel-Baset et al., 2019), TOPSIS (Nancy and Garg, 2019; Biswas et al., 2016), AHP (Bolturk and Kahraman, 2018), and fuzzy cognitive maps (Ferreira and Meidutè-Kavaliauskienė, 2019). We present some basic definitions of the NST here.

Definition A.1: Neutrosophic set (NS) (Smarandache, 1999) Let $U$ be a universal discourse and let $x$ signify a generic element in $U$. The NS $A$ in $U$ is characterized by a truth-membership function $T_{A}(x)$, an indeterminacy-membership function $I_{A}(x)$ and a falsity-membership function $F_{A}(x)$. The $T_{A}(x), I_{A}(x)$ and $F_{A}(x)$ are elements of $] 0^{-}, 1^{+}\left[\right.$, where $1^{+}=1+$ and $0=0$ are non-standard finite numbers. The NS can be represented as Equation (A.1). Note that $0^{-} \leq T_{A}(x)+I_{A}(x)+F_{A}(x) \leq 3^{+}$

$$
A=\left\{\left\langle x,\left(T_{A}(x), I_{A}(x), F_{A}(x)\right)\right\rangle: x \in U, T_{A}(x), I_{A}(x), F_{A}(x) \in\right] 0^{-}, 1^{+}[\}
$$

Definition A.2: Single-valued neutrosophic set (SVNS) (Wang et al., 2010) Let $U$ be a universal discourse, and let $x$ signify a generic element in $U$. The SVNS $A$ in $U$ is characterized by a truth-membership function $T_{A}(x)$, an indeterminacy-membership function $I_{A}(x)$ and a falsitymembership function $F_{A}(x)$. The $T_{A}(x), I_{A}(x)$ and $F_{A}(x)$ are real numbers of $[0,1]$. The SVNS can be represented as Equation (A.2). Note that $0 \leq T_{A}(x)+I_{A}(x)+F_{A}(x) \leq 3$

$$
A=\left\{\left\langle x,\left(T_{A}(x), I_{A}(x), F_{A}(x)\right)\right\rangle: x \in U, T_{A}(x), I_{A}(x), F_{A}(x) \in[0,1]\right\}
$$

Definition A.3: Single-valued trapezoidal neutrosophic number (SVTNN) (Deli and Subas, 2014) A SVTNN $\tilde{a}=\left\langle\left(a_{1}, b_{1}, c_{1}, d_{1}\right) ; w_{\tilde{a}}, u_{\tilde{a}}, y_{\tilde{a}}\right\rangle$ is a particular SVNN where $w_{\tilde{a}}, u_{\tilde{a}}, y_{\tilde{a}} \in[0,1]$ and 
$a_{1}, b_{1}, c_{1}, d_{1} \in \mathbb{R}$ then $T_{\tilde{a}}(x), I_{\tilde{a}}(x)$ and $F_{\tilde{a}}(x)$ are presented as Equations (A.3) to (A.5) respectively.

$$
\begin{aligned}
& T_{\tilde{a}}(x)=\left\{\begin{array}{cc}
\frac{\left(x-a_{1}\right) w_{\tilde{a}}}{\left(b_{1}-a_{1}\right)} \quad a_{1} \leq x<b_{1} \\
w_{\tilde{a}} \quad b_{1} \leq x \leq c_{1} \\
\frac{\left(d_{1}-x\right) w_{\tilde{a}}}{\left(d_{1}-c_{1}\right)} \quad c_{1}<x \leq d_{1}
\end{array}\right. \\
& 0 \text { otherwise } \\
& I_{\tilde{a}}(x)=\left\{\begin{array}{cc}
\frac{\left(b_{1}-x+u_{\tilde{a}}\left(x-a_{1}\right)\right)}{\left(b_{1}-a_{1}\right)} & a_{1} \leq x<b_{1} \\
u_{\tilde{a}} \quad b_{1} \leq x \leq c_{1} \\
\frac{\left(x-c_{1}+u_{\tilde{a}}\left(d_{1}-x\right)\right)}{\left(d_{1}-c_{1}\right)} & c_{1}<x \leq d_{1}
\end{array}\right. \\
& 1 \text { otherwise } \\
& F_{\tilde{a}}(x)=\left\{\begin{array}{cc}
\frac{\left(b_{1}-x+y_{\tilde{a}}\left(x-a_{1}\right)\right)}{\left(b_{1}-a_{1}\right)} \quad a_{1} \leq x<b_{1} \\
y_{\tilde{a}} \quad b_{1} \leq x \leq c_{1} \\
\frac{\left(x-c_{1}+y_{\tilde{a}}\left(d_{1}-x\right)\right)}{\left(d_{1}-c_{1}\right)} & c_{1}<x \leq d_{1}
\end{array}\right. \\
& 1 \text { otherwise }
\end{aligned}
$$

Definition A.4: Score function of a SVTNN (Wang and Zhong, 2009; Ye, 2017) Let $\tilde{a}=\left\langle(a, b, c, d) ; w_{\tilde{a}}, u_{\tilde{a}}, y_{\tilde{a}}\right\rangle$ be a SVTNN. Then the score function of $\tilde{a}$ (i.e., $S(\tilde{a}) \in[0,1]$ ) can be calculated according to Equation (A.6).

$$
S(\tilde{a})=\frac{1}{12}(a+b+c+d)\left(2+w_{\tilde{a}}-u_{\tilde{a}}-y_{\tilde{a}}\right)
$$




\section{Appendix B: Acquiring DMs' confidence in the best-to-others and the others-to-worst preferences}

Q1. Reflecting on your chosen best criterion and your provided preferences, to what degree do you have confidence in your provided best-to-others preferences? Please choose one of the following choices:

\begin{tabular}{|c|c|c|c|c|c|c}
$\square$ No Confidence & $\begin{array}{c}\square \text { Low } \\
\text { Confidence }\end{array}$ & $\begin{array}{c}\square \text { Fairly Low } \\
\text { Confidence }\end{array}$ & $\begin{array}{c}\square \text { Moderate } \\
\text { Confidence }\end{array}$ & $\begin{array}{c}\square \text { Fairly High } \\
\text { Confidence }\end{array}$ & $\begin{array}{c}\square \text { High } \\
\text { Confidence }\end{array}$ & $\begin{array}{c}\square \text { Absolute } \\
\text { Confidence }\end{array}$ \\
\hline
\end{tabular}

Q2. Reflecting on your chosen worst criterion and your provided preferences, to what degree do you have confidence in your provided others-to-worst preferences? Please choose one of the following choices:

\begin{tabular}{|c|c|c|c|c|c|c|}
\hline$\square$ No Confidence & $\begin{array}{c}\square \text { Low } \\
\text { Confidence }\end{array}$ & $\begin{array}{c}\square \text { Fairly Low } \\
\text { Confidence }\end{array}$ & $\begin{array}{c}\square \text { Moderate } \\
\text { Confidence }\end{array}$ & $\begin{array}{c}\square \text { Fairly High } \\
\text { Confidence }\end{array}$ & $\begin{array}{c}\square \text { High } \\
\text { Confidence }\end{array}$ & $\begin{array}{c}\square \text { Absolute } \\
\text { Confidence }\end{array}$ \\
\hline
\end{tabular}

\section{Appendix C: The CI values}

In this appendix, $C I$ values corresponding to various $a_{B W}, \rho^{+}$and $\rho^{-}$values have been shown. Note that by swapping values for $\rho^{+}$and $\rho^{-}$the $C I$ values will not change ${ }^{16}$. Thus, for convenience, we have shown those $\rho^{-}$and $\rho^{+}$values that produce unique $C I$ values. The $C I$ values for $a_{B W}=1$ are not shown because the best and worst criteria cannot be equally important.

\begin{tabular}{|c|c|c|c|c|c|c|c|c|c|}
\hline$\rho^{+}$ & $\rho^{-}$ & $a_{B W}=2$ & $a_{B W}=3$ & $a_{B W}=4$ & $a_{B W}=5$ & $a_{B W}=6$ & $a_{B W}=7$ & $a_{B W}=8$ & $a_{B W}=9$ \\
\hline 0.26 & 0.26 & 0.092 & 0.218 & 0.363 & 0.520 & 0.687 & 0.860 & 1.040 & 1.224 \\
\hline 0.26 & 0.38 & 0.109 & 0.257 & 0.428 & 0.612 & 0.807 & 1.010 & 1.218 & 1.432 \\
\hline 0.26 & 0.50 & 0.120 & 0.283 & 0.468 & 0.668 & 0.878 & 1.095 & 1.318 & 1.546 \\
\hline 0.26 & 0.68 & 0.132 & 0.307 & 0.506 & 0.718 & 0.941 & 1.169 & 1.403 & 1.641 \\
\hline 0.26 & 0.90 & 0.140 & 0.325 & 0.533 & 0.754 & 0.984 & 1.219 & 1.459 & 1.702 \\
\hline 0.26 & 1.00 & 0.143 & 0.331 & 0.542 & 0.765 & 0.997 & 1.235 & 1.476 & 1.721 \\
\hline 0.38 & 0.38 & 0.135 & 0.318 & 0.530 & 0.760 & 1.004 & 1.258 & 1.520 & 1.789 \\
\hline 0.38 & 0.50 & 0.153 & 0.361 & 0.600 & 0.860 & 1.134 & 1.420 & 1.715 & 2.017 \\
\hline 0.38 & 0.68 & 0.172 & 0.404 & 0.670 & 0.956 & 1.258 & 1.571 & 1.892 & 2.220 \\
\hline 0.38 & 0.90 & 0.187 & 0.438 & 0.723 & 1.028 & 1.348 & 1.678 & 2.015 & 2.358 \\
\hline 0.38 & 1.00 & 0.193 & 0.450 & 0.740 & 1.051 & 1.376 & 1.711 & 2.053 & 2.400 \\
\hline 0.50 & 0.50 & 0.177 & 0.419 & 0.697 & 1.000 & 1.321 & 1.655 & 2.000 & 2.354 \\
\hline 0.50 & 0.68 & 0.204 & 0.481 & 0.800 & 1.146 & 1.511 & 1.892 & 2.284 & 2.686 \\
\hline 0.50 & 0.90 & 0.227 & 0.533 & 0.883 & 1.261 & 1.658 & 2.070 & 2.493 & 2.926 \\
\hline 0.50 & 1.00 & 0.234 & 0.551 & 0.911 & 1.298 & 1.706 & 2.127 & 2.559 & 3.000 \\
\hline 0.68 & 0.68 & 0.241 & 0.570 & 0.948 & 1.360 & 1.796 & 2.251 & 2.720 & 3.202 \\
\hline 0.68 & 0.90 & 0.274 & 0.647 & 1.076 & 1.542 & 2.034 & 2.547 & 3.075 & 3.617 \\
\hline 0.68 & 1.00 & 0.286 & 0.675 & 1.121 & 1.605 & 2.115 & 2.646 & 3.193 & 3.752 \\
\hline 0.90 & 0.90 & 0.319 & 0.754 & 1.255 & 1.800 & 2.377 & 2.979 & 3.600 & 4.238 \\
\hline 0.90 & 1.00 & 0.336 & 0.793 & 1.320 & 1.893 & 2.500 & 3.132 & 3.785 & 4.455 \\
\hline 1.00 & 1.00 & 0.354 & 0.838 & 1.394 & 2.000 & 2.641 & 3.310 & 4.000 & 4.708 \\
\hline
\end{tabular}

${ }^{16}$ The reason for that is clear in Equation (9) as interchanging $\rho^{+}$and $\rho^{-}$would not produce a new solution. For instance, for $a_{B W}=2$ and $\rho^{-}=0.68$ and $\rho^{+}=0.90$ the $C I$ would be $C I=0.274$ which is the same $C I$ value for $a_{B W}=2$ and $\rho^{-}=0.90$ and $\rho^{+}=0.68$. 